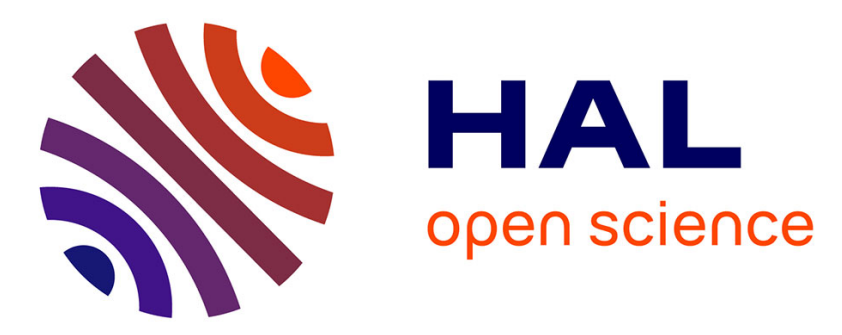

\title{
Sensitivity analysis of conceptual model calibration to initialisation bias. Application to karst spring discharge models
}

Naomi Mazzilli, Vincent Guinot, Hervé Jourde

\section{- To cite this version:}

Naomi Mazzilli, Vincent Guinot, Hervé Jourde. Sensitivity analysis of conceptual model calibration to initialisation bias. Application to karst spring discharge models. Advances in Water Resources, 2012, 42, pp.1-16. 10.1016/j.advwatres.2012.03.020 . hal-00804648

\section{HAL Id: hal-00804648 \\ https://hal.science/hal-00804648}

Submitted on 26 Mar 2013

HAL is a multi-disciplinary open access archive for the deposit and dissemination of scientific research documents, whether they are published or not. The documents may come from teaching and research institutions in France or abroad, or from public or private research centers.
L'archive ouverte pluridisciplinaire HAL, est destinée au dépôt et à la diffusion de documents scientifiques de niveau recherche, publiés ou non, émanant des établissements d'enseignement et de recherche français ou étrangers, des laboratoires publics ou privés. 


\title{
Sensitivity analysis of conceptual model calibration to initialisation bias. Application to karst spring discharge models.
}

\author{
N. Mazzillia,*, V. Guinot ${ }^{\mathrm{a}}$, H. Jourde ${ }^{\mathrm{a}}$ \\ ${ }^{a}$ HydroSciences Montpellier, UMR 5569 (CNRS, IRD, UM1, UM2), Université Montpellier 2, CC MSE, 34095 Montpellier \\ Cedex 5, France
}

\begin{abstract}
In this paper the perturbation approach is used to investigate the analytical properties of the sensitivity to the initial conditions on the calibration and simulation results of two karst spring discharge reservoir models. The propagation of uncertainty in the initial conditions is shown to depend on both model structure and the values assumed by state variables at the beginning of simulation. Depending on model structure, nonlinearity may either hasten or delay the dissipation of the initialisation bias. In particular, threshold-based transfer functions are shown to generate Dirac sensitivity patterns. When associated with long-term memory reservoir and fast discharge models, they may generate a substantial initialisation bias even after very long periods of inactivity. As a practical consequence, the commonly-used one year warm-up period may not be sufficient to dissipate the initialisation bias. Calibration results may be impacted significantly. A careful examination of the initialisation bias behaviour should be part of "good modelling practice". In particular, the use of elaborate procedures for locating the global optimum of the objective function used for parameter optimization can only be justified in so far as the initialisation bias has been efficiently eliminated. This study advocates the use of local sensitivity analysis as a low-computational cost tool to identify the main characteristics of the bias behaviour, even for conceptual models with strongly non-linear transfer functions.
\end{abstract}

Keywords: initialisation bias, initial conditions, conceptual reservoir model, perturbation approach, model sensitivity, model calibration

\section{Introduction}

Numerical models are important tools for groundwater management. Good model development practices include the assessment of model performance but also of model uncertainty and physical realism [1]. This paper focuses on the influence of initial conditions on the calibration and simulation results of two reservoir models for karst spring discharge.

Specifying the initial state of a given model inevitably leads to an initialisation bias in model output, because an experimental assessment of the internal state of lumped models is not possible. If the error in the initial values assigned to the internal variables is too important, the initialisation bias may affect the calibration or the simulation result significantly. Two main approaches are adopted to address the issue of initialisation bias in conceptual hydrological modelling: (i) the calibration of the initial state estimate (by Kalman filter-based $[2,3,4]$ or e.g. variational methods [5]), and (ii) the truncation of the model output $[6,7]$. The calibration method is generally used in an operational flood forecasting context, whereas the output truncation method is usually preferred for continous time modelling for example in groundwater resource management. The output truncation method consists in running the model for a sufficiently long time to make the initialisation bias negligible before retaining data for analysis. The period after which the model output variables become independent from the initialisation bias is called the warm-up period.

\footnotetext{
*Corresponding author

Email address: mazzilli@msem.univ-montp2.fr (N. Mazzilli)
} 
A good a priori estimate of the model initial state is required for both the calibration of the initial state [2] and the truncation of the model output. The availability of realistic initial state estimates is all the more challenging if the modelling time scale is short. At the monthly or annual time scale, relevant initial state estimates can be obtained by running the model with mean meteorological inputs until a steady state is reached [8], but such a procedure may turn out to be irrelevant for strongly non-linear models. At the daily time step, the computational cost of the steady state method becomes important and the definition of a mean meteorological time series is problematic [9]. Under certain conditions, the steady state can be estimated by analytical procedures [9].

The choice of the calibration or warm-up period is strongly linked to the sensitivity of the model output to the initial conditions. Indeed, calibration should be performed over periods when the model output is sensitive to the calibration parameter. Conversely, the warm-up period should stop as soon as the model output becomes insensitive to the initial state, in order to preserve as much data as possible for the analysis. The issue of an optimal determination of the warm-up period for reservoir-based models has been little addressed in the literature. So has been the issue of the consequence of an improperly chosen warm-up period on calibration results. This paper investigates the influence of model non-linearity on the sensitivity behaviour based on the local perturbation approach. The perturbation technique provides theoretical insights into the general behaviour of the sensitivity to the initial conditions. The analysis is carried out for two reservoir models that have both been validated on the application site selected for this study by previous authors [10,7]. The main issues addressed are: (i) does model structure have consequences on the length of the warm-up period, (ii) can guidelines be defined for the choice of the warm-up period, so as to minimize the impact of the initialisation bias on model calibration ?

The present work is structured in the following way. The application site is presented in Section 2 . Sections 2.2 and 2.3 detail the structure and governing equations for the Vensim and the hysteresis-based models respectively. Section 3 briefly presents the perturbation approach used for the derivation of the sensitivity equations and the sensitivity for two rainfall-discharge models specifically designed for karst system modelling. The sensitivity properties are exemplified by real-world applications in Section 4 . Section 5 focuses on the estimation of the uncertainty on the calibration results. Section 6 is devoted to a discussion and Section 7 is devoted to the conclusion and to practical recommandations.

\section{Application site and models}

\subsection{Site and data}

The Durzon karst system is located in the Grands Causses area in the Southern Massif Central (France). This Vauclusian karst system is embedded in a 400m thick formation of middle to upper Jurassic limestones and dolomites, deposited on top of a 200m thick formation of upper-Liassic marls [11]. This latter formation constitutes the aquifer bedrock. The North Eastern and Southern boundaries of the system are delimited by thrust faults. The other boundaries are delimited by the topography. The main outlet of the catchment is the Durzon spring, which is located in the Northern part of the catchment (see Figure 1). The recharge area estimates range from 100 to $120 \mathrm{~km}^{2}$ based on geomorphological characteristics, mass balance and tracing experiments [11, 12]. Following [10] and [7], a recharge area of $116.8 \mathrm{~km}^{2}$ is used in the present study.

Discharge data is available for the catchment main outlet only. The Durzon spring discharges measured over the 2001-2008 period range from 0.5 to $18 \mathrm{~m}^{3} / \mathrm{s}$, with an average of $1.4 \mathrm{~m}^{3} / \mathrm{s}$. Note that since the measured variable is the water level at the spring pool, discharge values must be derived by application of a stage-discharge relationship [7]. The stage-discharge relationship is fitted to in situ measurements. Various fitting criteria may yield equally acceptable stage-discharge relationships. For a given water level, the comparison of discharge values obtained using different fitting criteria yields an uncertainty of about $3 \%$ on the discharge value [7].

Meteorological data are measured at the "Le Caylar" Meteo-France meteorological station, some $10 \mathrm{~km}$ S-SE of the Durzon spring. The average of annual rainfall for the $2001-2008$ period is $1069 \mathrm{~mm}$. The average of daily temperatures range from -8 to $+28^{\circ} \mathrm{C}$. The average of annual temperature is $10^{\circ} \mathrm{C}$. The daily 


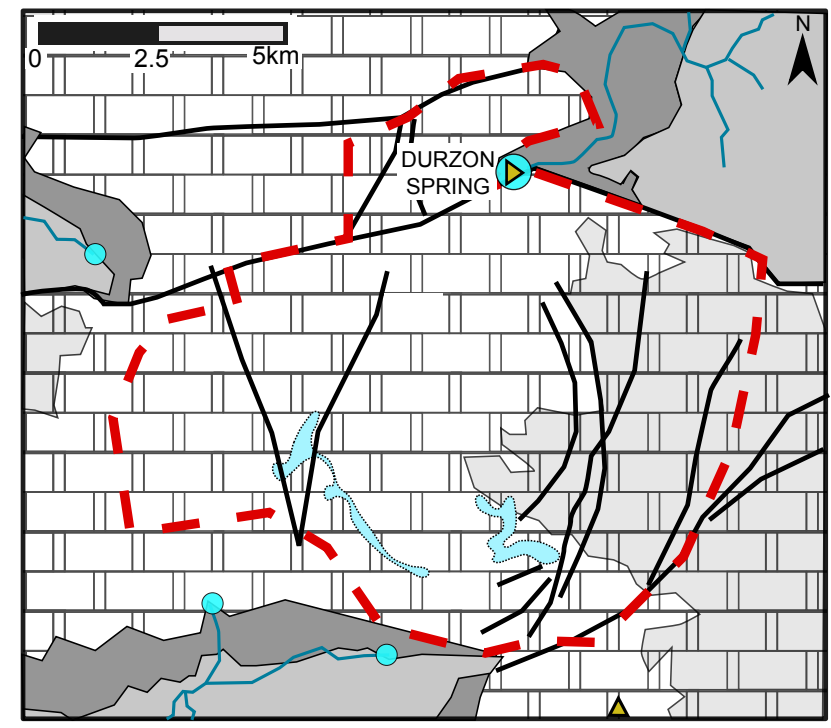

Hydrogeological framework

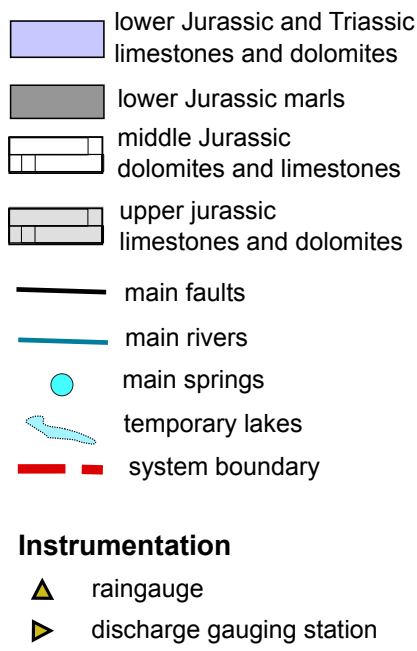

Figure 1: Hydrogeological framework and instrumentation of the Durzon area. Modified after [11, 12, 14].

potential evapotranspiration is estimated from the monthly potential evapotranspiration (computed using Thornthwaite's formula [13]) using a sine function-based interpolation, as proposed in [7]

$$
\operatorname{PET}(t)=\left[1-a \cos \left(2 \pi \frac{t-t_{\text {min }}}{T}\right)\right] \overline{\mathrm{PET}}
$$

where $t$ is the time where the PET is to be interpolated, $\overline{\mathrm{PET}}$ is the average value of the PET series computed from Thornthwaite's formula, $T$ is the period of the PET signal (one year), $t_{\min }$ is the time at which the PET is minimum and $a$ is the dimensionless amplitude of the signal. The parameters $t_{\min }$ and $a$ have been estimated by means of a classical least-squares optimization procedure by [7] (see parameter values in Table 1 and see PET time series in Figure 2).

\subsection{Hysteresis-based model}

The hysteresis-based model (Figure 3a) has been proposed in [7] and validated for the simulation of the Durzon karst spring discharge. The hysteresis-based model is made of two reservoirs. The upper reservoir $\mathrm{H}$ represents the epikarst and soil zones. The lower reservoir L represents the saturated and vadose zones. The model functioning may be described as follows.

1. The epikarst reservoir $\mathrm{H}$ receives the incoming precipitations and is affected by evapotranspiration. Note that the epikarst reservoir may fall dry.

2. Part of the water contained in the reservoir $\mathrm{H}$ leaks to the lower reservoir $\mathrm{L}$ (discharge $Q_{\mathrm{HL}}$ ) via a linear discharge relationship. This flux accounts for the classical recharge process to the saturated zone.

\begin{tabular}{lll}
\hline Symbol & Meaning & Value \\
\hline$a$ & Dimensionless amplitude of the sine wave & 0.8 \\
$t_{\min }$ & Time of minimum PET & 15 January \\
$T$ & Period of the interpolation function & $1 \mathrm{yr}$ \\
$\overline{\text { PET }}$ & Average potential evapotranspiration rate & $1.95 \mathrm{~mm} / \mathrm{d}$ \\
\hline
\end{tabular}

Table 1: Parameters for the potential evapotranspiration model. 


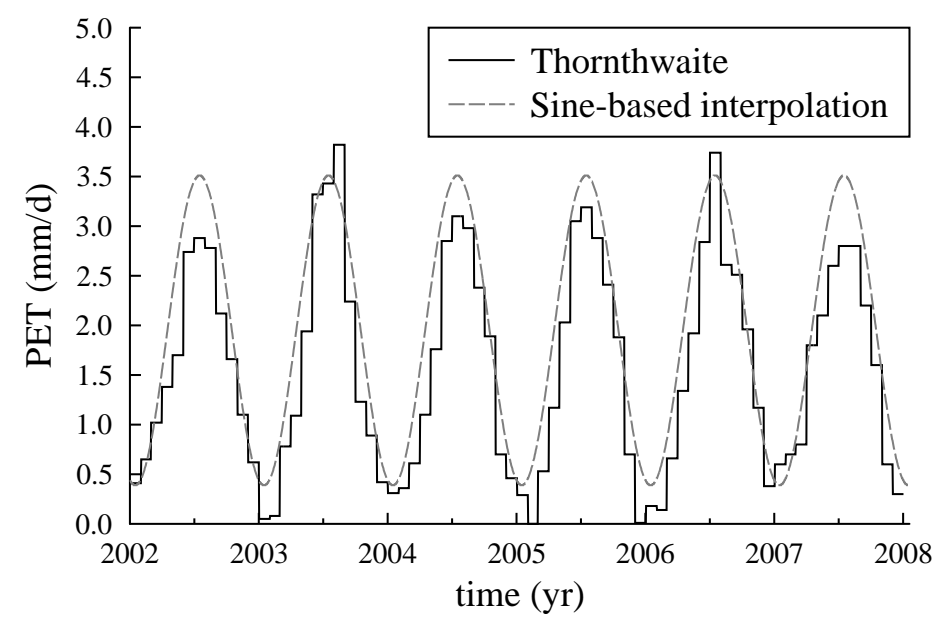

Figure 2: Potential evapotranspiration rate. Black line: monthly values computed using Thornthwaite's formula. Grey line: daily values interpolated based on equation (1) [7].

3. Part of the water contained in $\mathrm{H}$ may flow outside of the catchment (discharge $Q_{\mathrm{sec}}$ ), provided that the water level in $\mathrm{H}$ exceeds a given threshold $H_{\mathrm{sec}}$. This flux accounts for the activation of temporary, secondary springs when the connectivity of the epikarst zone is sufficient.

4. Part of the water contained in $\mathrm{H}$ may flow directly to the outlet of the catchment (discharge $Q_{\mathrm{HY}}$ ). Physically, such a connection is allowed by a network of fractures and karst conduits. It is responsible for the fast component of the catchment response to rainfall events.

5. The water in the lower reservoir $\mathrm{L}$ leaks to the outlet of the catchment (discharge $Q_{L}$ ) via a classical, linear discharge relationship.

The nonlinear, hysteretic transfer function used to model the discharge $Q_{\mathrm{HY}}$ constitutes the main originality of the model. As in most models, the water level in the epikarst reservoir $\mathrm{H}$ must reach a given threshold $H_{2}$ before the connectivity of the karst system becomes nonzero and the fast response flow $Q_{\mathrm{HY}}$ is initiated. However, karst connectivity is preserved until the water level in $\mathrm{H}$ drops below a lower threshold $H_{1}<H_{2}$ (hysteretic transfer). This behaviour can be compared to that of a siphon. It traduces the fact that, for a given matric potential, the water content (and thus the connectivity of the medium) is higher during the drying cycle than during the wetting cycle. The nonlinear function used to model $Q_{\mathrm{HY}}$ accounts for the influence of the amount of water stored in the soil and epikarst reservoir on the conveyance area of the flow.

The mass balance equations of the hysteresis-based model are the following:

$$
\begin{aligned}
& \frac{\mathrm{d} H}{d t}= \begin{cases}P-\mathrm{ET}-Q_{\mathrm{sec}}-Q_{\mathrm{HY}}-Q_{\mathrm{HL}} & \text { if } H>0 \\
\max (P-\mathrm{ET}, 0) & \text { if } H=0\end{cases} \\
& \frac{\mathrm{d} L}{d t}=Q_{\mathrm{HL}}-Q_{\mathrm{L}}
\end{aligned}
$$

where $H$ and $L$ are the water levels in the reservoirs $\mathrm{H}$ and $\mathrm{L}$ respectively, $P$ is the precipitation rate, $\mathrm{ET}$ is the evapotranspiration rate, $Q_{\mathrm{sec}}$ is the secondary springs discharge, $Q_{\mathrm{HY}}$ is the fast flow component through the epikarst zone to the outlet of the catchment, $Q_{\mathrm{HL}}$ is the infiltration rate to the lower reservoir and $Q_{\mathrm{L}}$ is the baseflow discharge from the lower reservoir $L$ to the outlet of the catchment. Note that discharges are expressed as specific discharge. Both the evapotranspiration and the infiltration stop when the water level reaches the minimum value $H=0$ (see equation (2a)), which prevents the reservoir from becoming too seriously under-saturated. 
The internal fluxes are assumed to obey the following relationships

$$
\begin{aligned}
Q_{\mathrm{sec}} & =\varepsilon_{\mathrm{sec}} k_{\mathrm{sec}}\left(H-H_{\mathrm{sec}}\right) \\
Q_{\mathrm{HY}} & =\varepsilon_{\mathrm{HY}} k_{\mathrm{HY}}\left(\frac{H-H_{1}}{H_{2}-H_{1}}\right)^{\alpha} \\
Q_{\mathrm{HL}} & =k_{\mathrm{HL}} H \\
Q_{\mathrm{L}} & =k_{\mathrm{L}} L
\end{aligned}
$$

where $k_{\mathrm{sec}}, k_{\mathrm{HY}}, k_{\mathrm{HL}}$ and $k_{L}$ are specific discharge coefficients, $\alpha$ is a positive exponent, $H_{\mathrm{sec}}$ is the threshold level in reservoir $\mathrm{H}$ above which the secondary springs are activated, $H_{1}$ and $H_{2}$ are the lower and upper threshold levels for the hysteretic discharge function respectively, and $\varepsilon_{\mathrm{sec}}$ and $\varepsilon_{\mathrm{HY}}$ are indicators of the secondary springs activation and of the karst system connectivity respectively. The fact that the baseflow discharge $Q_{\mathrm{L}}$ is modeled by a linear discharge relationship (see equation $(3 \mathrm{~d})$ ) means that the reservoir $\mathrm{L}$ cannot fall dry. The indicator of the secondary springs activation $\varepsilon_{\text {sec }}$ is defined as

$$
\varepsilon_{\mathrm{sec}}= \begin{cases}1 & \text { if } H>H_{\mathrm{sec}} \\ 0 & \text { if } H \leq H_{\mathrm{sec}}\end{cases}
$$

The indicator of the karst system connectivity is switched to 1 if $H$ rises above $H_{2}$ and it is switched to 0 if $H$ falls below $H_{1}$

$$
\begin{aligned}
& \left.\begin{array}{ll}
\varepsilon_{\mathrm{HY}} & =0 \\
H & =H_{2}
\end{array}\right\} \Rightarrow \varepsilon_{\mathrm{HY}}=1 \\
& \left.\begin{array}{ll}
\varepsilon_{\mathrm{HY}} & =1 \\
H & =H_{1}
\end{array}\right\} \Rightarrow \varepsilon_{\mathrm{HY}}=0
\end{aligned}
$$

The actual evapotranspiration rate is assumed to be equal to the potential evapotranspiration rate as long as the soil-epikarst reservoir $\mathrm{H}$ is not empty

$$
\mathrm{ET}= \begin{cases}\mathrm{PET} & \text { if } H>0 \\ 0 & \text { if } H=0\end{cases}
$$

The discharge at the outlet of the catchment $Q$ is defined as the sum of the epikarstic $Q_{\mathrm{HY}}$ and baseflow $Q_{L}$ discharges, multiplied by the total area of the catchement $A$.

$$
Q=A\left(Q_{\mathrm{HY}}+Q_{L}\right)
$$

\subsection{Vensim model}

The Vensim model has been proposed in [10]. It is based on the Bemer [15] and Medor [16] models. The model has been validated over four karst springs located on the Larzac plateau [10]. In the following, this model will be termed the Vensim model from the modelling platform used for its implementation by [10].

The Vensim model is made of three reservoirs (see model structure in Figure 3b). The upper reservoir $\mathrm{H}$ represents the soil zone. The lower reservoir $\mathrm{S}$ accounts for the long-time storage that occurs mainly within the saturated zone. The lower reservoir $\mathrm{R}$ accounts for the rapid infiltration towards the outlet through fractures and karst conduits. Possible secondary springs are neglected. The model functioning may be described as follows.

1. The epikarst reservoir $\mathrm{H}$ receives the incoming precipitations and is affected by evapotranspiration. Evapotranspiration stops when the water level reaches a minimum value $H_{\min }$.

2. Part of the water contained in the reservoir $\mathrm{H}$ leaks to the lower reservoirs $\mathrm{S}$ and $\mathrm{R}$, provided that the water level in $\mathrm{H}$ is larger than zero. Note that the infiltration from the reservoir $\mathrm{H}$ to the reservoirs $\mathrm{H}$ and $\mathrm{S}$ is modeled as an all-or-nothing process. 
3. The distribution of $Q_{\mathrm{H}}$ between the $\mathrm{S}$ and $\mathrm{R}$ reservoirs depends on the water level in the reservoir $\mathrm{S}$. When the water level in $\mathrm{S}$ rises above a threshold value $S_{\text {sill }}$, the proportion of water routed to the reservoir $\mathrm{R}$ increases. This accounts for the influence of the karst connectivity on the catchment response.

4. The water in the lower reservoirs $\mathrm{S}$ and $\mathrm{R}$ leaks to the outlet of the catchment via classical, linear discharge relationships.

The use of threshold transfer functions in both the Vensim and the hysteresis-based models is justified by the consideration of the threshold transfer process within the karst system [17, 18, 19]. However, the models differ in the conceptualization of the threshold transfer. In particular, in the Vensim model the switch in the distribution coefficient is associated with the water level in the long-term storage, saturated zone reservoir. In the hysteresis-based model, all threshold transfer functions are associated with the water level in the soil-epikarst reservoir. Note that the time constants associated with the saturated zone and the soil-epikarst reservoirs are expected to differ by at least one order of magnitude. The implications of this on the sensitivity behaviour are discussed in Section 3.

The mass balance equations of the Vensim model are the following:

$$
\begin{aligned}
\frac{\mathrm{d} H}{d t} & =\left\{\begin{array}{cl}
P-\mathrm{ET}-Q_{\mathrm{H}} & \text { if } H_{\min }<H \leq 0 \\
\max (P-\mathrm{ET}, 0) & \text { if } H=H_{\min }
\end{array}\right. \\
\frac{\mathrm{d} S}{d t} & =X Q_{\mathrm{H}}-Q_{\mathrm{S}} \\
\frac{\mathrm{d} R}{d t} & =(1-X) Q_{\mathrm{H}}-Q_{\mathrm{R}}
\end{aligned}
$$

with

$$
X= \begin{cases}X_{\mathrm{D}} & \text { if } S \leq S_{\text {sill }} \\ X_{\mathrm{W}} & \text { if } S>S_{\text {sill }}\end{cases}
$$

$H, R$ and $S$ are the water levels in the reservoir $\mathrm{H}, \mathrm{R}$ and $\mathrm{S}$ respectively, $P$ is the precipitation rate, ET is the evapotranspiration rate, $H_{\min }$ is the minimum water level admissible in the reservoir $\mathrm{H}, Q_{\mathrm{H}}$ is the total discharge rate from the reservoir $\mathrm{H}$ towards the rapid and slow drainage reservoirs, $Q_{\mathrm{R}}$ and $Q_{\mathrm{S}}$ are the discharge rates from the reservoirs $\mathrm{R}$ and $\mathrm{S}$ respectively, $X_{\mathrm{W}}$ and $X_{\mathrm{D}}$ are the distribution coefficients for $Q_{\mathrm{H}}$ in high and low water level periods respectively $\left(X_{\mathrm{D}}>X_{\mathrm{W}}\right)$ and $S_{\text {sill }}$ is the threshold level that triggers the switch in the distribution coefficient. The internal fluxes are assumed to obey the following relationships

$$
\begin{aligned}
Q_{\mathrm{H}} & =\varepsilon_{\mathrm{H}} \max (P-\mathrm{ET}, 0) \\
Q_{\mathrm{S}} & =k_{\mathrm{S}} S \\
Q_{\mathrm{R}} & =k_{\mathrm{R}} R
\end{aligned}
$$

where $k_{\mathrm{R}}$ and $k_{\mathrm{S}}$ are specific discharge coefficients and $\varepsilon_{\mathrm{H}}$ is defined by the following relation

$$
\varepsilon_{\mathrm{H}}= \begin{cases}1 & \text { if } H=0 \\ 0 & \text { if } H<0\end{cases}
$$

The discharge at the outlet of the catchment $Q$ is defined as the sum of the specific discharges $Q_{\mathrm{R}}$ and $Q_{\mathrm{S}}$, multiplied by the total area of the catchement $A$.

$$
Q=A\left(Q_{\mathrm{R}}+Q_{\mathrm{S}}\right)
$$

\section{Sensitivity analysis}

\subsection{Presentation of the perturbation approach}

The perturbation approach is based upon a linear approximation of the model equations in the vicinity of a central value. The approach provides an in-depth insight into the model behaviour, at little computational 
a)

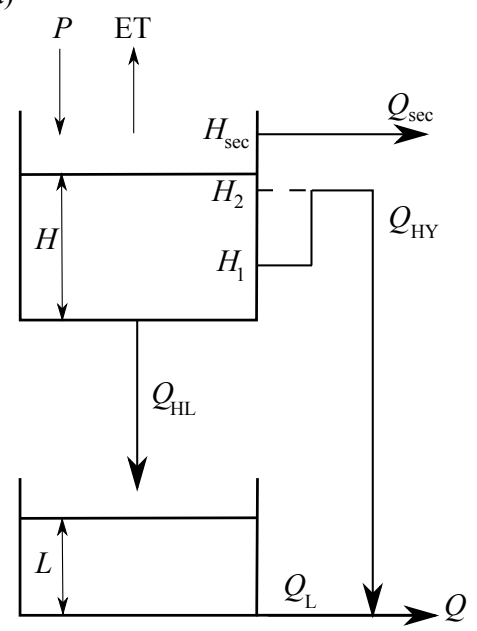

b)

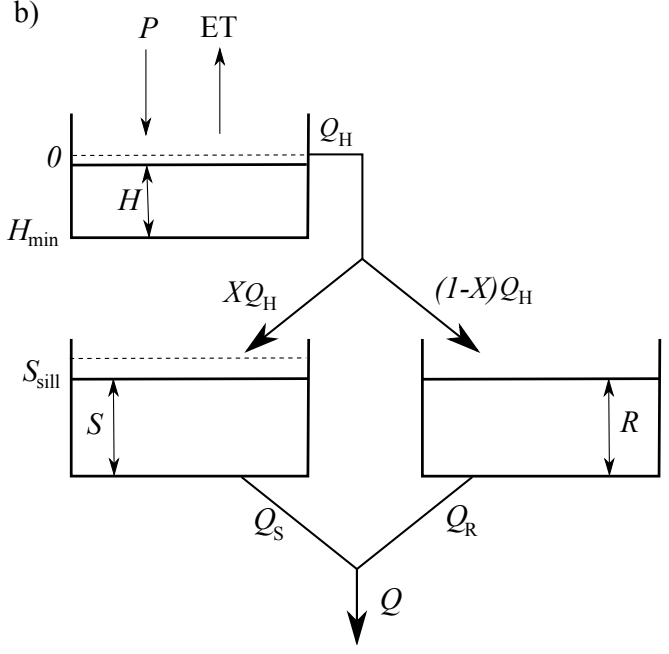

Figure 3: Structure and notations for: a) the hysteresis-based model [7], b) the Vensim model [10].

cost. A short presentation of the perturbation method is given hereafter. More details on sensitivity calculation can be found in e.g. [20].

The sensitivity equations are derived by carrying out a perturbation analysis of the model equations. Let $\phi$ be the parameter with respect to which the sensitivity analysis is carried out. The model balance equations $(2 \mathrm{a}-\mathrm{b})$ and $(8 \mathrm{a}-\mathrm{c})$ can be rewritten in a more general manner as

$$
\frac{\partial U}{\partial t}=f(U, \phi, t)
$$

where $U$ is the variable vector and $\phi$ is the parameter vector. Differentiating equation (13) with respect to $\phi$ leads to

$$
\frac{\partial}{\partial t}\left(\frac{\partial U}{\partial \phi}\right)=\frac{\partial f}{\partial U} \frac{\partial U}{\partial \phi}+\frac{\partial f}{\partial \phi}
$$

The sensitivity of the variable $U$ to the parameter $\phi$ is defined as $\mathcal{U}_{\phi} \equiv \partial U / \partial \phi$. Then equation (14) may be rewritten as

$$
\frac{\partial \mathcal{U}_{\phi}}{\partial t}=\frac{\partial f}{\partial U} \mathcal{U}_{\phi}+\frac{\partial f}{\partial \phi}
$$

Similarly, the discharge $Q$ at the outlet can be expressed as

$$
Q=Q(U, \phi, t)
$$

The sensitivity of the discharge $Q$ to the parameter $\phi$ is defined as $\mathcal{Q}_{\phi} \equiv \partial Q / \partial \phi$. Differentiating equation (16) with respect to parameter $\phi$ leads to

$$
\mathcal{Q}_{\phi}=\frac{\partial Q}{\partial U} \mathcal{U}_{\phi}+\frac{\partial Q}{\partial \phi}
$$

\subsection{General sensitivity properties for the hysteresis-based model}

The sensitivity equations are derived using the perturbation approach presented in Section 3.1. The sensitivity equations are detailed in Appendix A.1. 


\subsubsection{Sensitivity to $L_{0}$}

The impact of the initial level $L_{0}$ on the simulated spring discharge decreases exponentially with a time constant $T=1 / k_{\mathrm{R}}$. Note that neither the activation of the hysteretic transfer nor the activation of the secondary springs nor the drying of the reservoir $\mathrm{H}$ have an impact on the sensitivities to the initial level $L_{0}$.

\subsubsection{Sensitivity to $H_{0}$}

Assume that neither the hysteretic transfert nor the secondary springs are activated. Also assume that the reservoir $\mathrm{H}$ does not dry out $(H>0)$. Then the governing equations for the sensitivity of $H, L$ and $Q$ to the initial water level $H_{0}$ in the reservoir $\mathrm{H}$ may be solved analytically, leading to

$$
\begin{aligned}
\mathcal{H}_{H_{0}} & =\exp \left(-k_{\mathrm{HL}} t\right) \\
\mathcal{L}_{H_{0}} & =\frac{k_{\mathrm{HL}}}{k_{L}-k_{\mathrm{HL}}}\left(\exp \left(-k_{\mathrm{HL}} t\right)-\exp \left(-k_{L} t\right)\right) \\
\mathcal{Q}_{H_{0}} & =A \frac{k_{\mathrm{HL}} k_{L}}{k_{L}-k_{\mathrm{HL}}}\left(\exp \left(-k_{\mathrm{HL}} t\right)-\exp \left(-k_{L} t\right)\right)
\end{aligned}
$$

The sensitivity of the spring discharge to $H_{0}$ reaches its maximum at time $t_{\max }=\ln \left(k_{L} / k_{\mathrm{HL}}\right) /\left(k_{L}-k_{\mathrm{HL}}\right)$.

The activation of the rapid transfer functions (hysteretic transfer or of the secondary springs) result in a faster decrease in $\mathcal{H}_{H_{0}}$ (see equation (A.1a)). It is also associated with an increase in the sensitivity $\mathcal{Q}_{H_{0}}$ (see equation (A.1d)). Heavy rainfall events therefore help erasing the influence of the initial water level $H_{0}$. In other words, heavy rainfall events make the minimal warm-up period shorter. However, since the influence of $H_{0}$ on the spring discharge $Q$ is increased during these rainfall events, care should be taken not to include these events within the calibration period.

The drying of the reservoir $\mathrm{H}$ results in the cancellation of $\mathcal{H}_{H_{0}}$ (see equation (A.2a)). After the emptying of the reservoir $\mathrm{H}$, the sensitivities $\mathcal{L}_{H_{0}}$ and $\mathcal{Q}_{H_{0}}$ decrease exponentially. Also note that subsequent filling of the reservoir $\mathrm{H}$ and the possible activation of the rapid transfert function will have no impact on the discharge sensitivity $\mathcal{Q}_{H_{0}}$. A complete emptying of the reservoir $\mathrm{H}$ therefore prevents the simulated discharge from subsequent artefacts due to a burst in $\mathcal{H}_{H_{0}}$ during the activation of the hysteretic transfer function.

\subsection{General sensitivity properties for the Vensim model}

The sensitivity equations are derived using the perturbation approach presented in Section 3.1. The sensitivities of the water levels in the reservoirs $\mathrm{H}, \mathrm{S}$ and $\mathrm{R}$ to the parameter $\phi$ are denoted by $\mathcal{H}_{\phi}$, $\mathcal{S}_{\phi}$ and $\mathcal{R}_{\phi}$ respectively. The sensitivity equations are given in Appendix A.2.

\subsubsection{Sensitivity to $R_{0}$}

The impact of the initial level $R_{0}$ on the simulated spring discharge decreases exponentially with a time constant $T=1 / k_{\mathrm{R}}$. Note that neither the activation of the hysteretic transfer nor the activation of the secondary springs nor the drying of the reservoir $\mathrm{H}$ have an impact on the sensitivities to the initial level $R_{0}$.

\subsubsection{Sensitivity to $S_{0}$}

The particularity of the Vensim model lies in the fact that the value of the distribution coefficient $X$ depends on the water level in the reservoir $\mathrm{S}$. This means that that the sensitivity of the level $R$ to the initial water level in $\mathrm{S}$ is non-zero (see equation (A.4c)).

Assume that the threshold $S_{\text {sill }}$ is not activated. Then the behaviour of the sensitivity to $S_{0}$ is similar to that of the sensitivity to $R_{0}$. The impact of the initial level $S_{0}$ on the simulated spring discharge decreases exponentially with a time constant $T=1 / k_{\mathrm{S}}$.

The activation of the threshold $S_{\text {sill }}$ results in a decrease in $\mathcal{S}_{S_{0}}$ and in an increase in $\mathcal{R}_{S_{0}}$, based on equations (A.4b) and (A.4c) (see Figure 4b). The activation of the threshold $S_{\text {sill }}$ thus hastens the disappearance of the influence of the initial condition $S_{0}$. On the other hand, an activation of $S_{\text {sill }}$ results in 

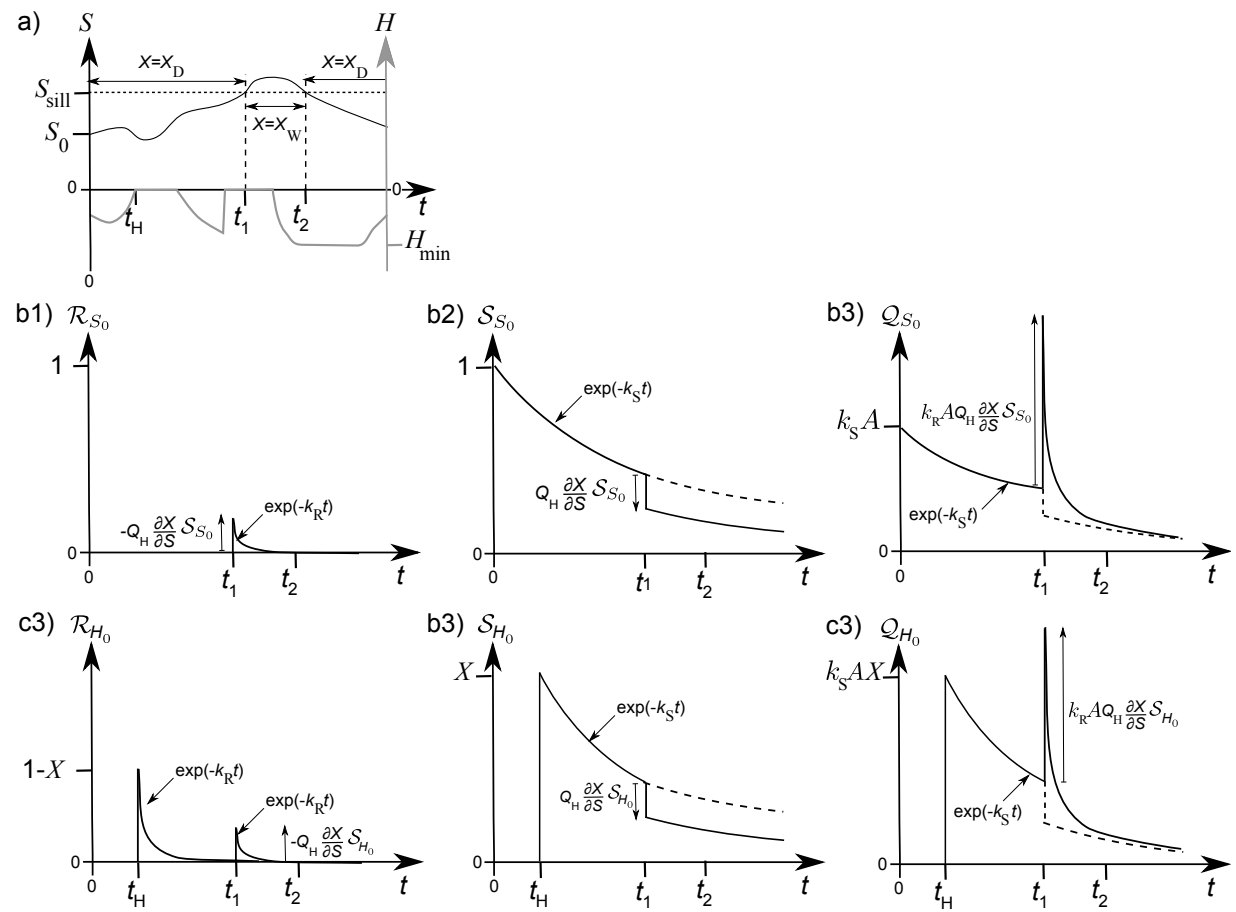

Figure 4: Vensim model. Typical behaviour of the sensitivities to $H_{0}$ and $S_{0}$ contingent on the reservoir $\mathrm{H}$ overflow and on the activation of the switch in the distribution coefficient. The reservoir $\mathrm{H}$ overflows for the first time at time $t_{H}$. The threshold $S_{\text {sill }}$ is activated at time $t_{1}$ and desactivated at time $t_{2}$. Graph a): water level in the reservoirs S (dark line) and $\mathrm{H}$ (bold, grey line), Graphs b): sensitivity of $R$ (graph b1), $S$ (graph b2) and $Q$ (graph b3) to the initial condition $S_{0}$, Graphs c): sensitivity of $R$ (graph c1), $S$ (graph c2) and $Q$ (graph c3) to the initial condition $H_{0}$. Note that the value of $\mathcal{Q}_{H_{0}}$ by the time of the first overflow is independent from the magnitude of the rainfall event that triggers the overflow.

a pulse for the sensitivity $\mathcal{R}_{S_{0}}$ of the water level in the reservoir $\mathrm{R}$ and therefore in a pulse for the sensitivity $\mathcal{Q}_{S_{0}}$ of the spring discharge.

The de-activation of the threshold $S_{\text {sill }}$ has no impact on the behaviour of the sensivities to $S_{0}$ (see Figure $4 \mathrm{~b}$ and see proof in Appendix Appendix A.2).

\subsubsection{Sensitivity to $H_{0}$}

The reservoir $\mathrm{H}$ differs from the reservoirs $\mathrm{S}$ and $\mathrm{R}$ in that its response is all-or-nothing. The sensitivity $\mathcal{H}_{H_{0}}$ is piecewise constant (see Figure 5). It is equal to one at the beginning of the simulation and it cancels when the reservoir $\mathrm{H}$ overflows for the first time $\left(\varepsilon_{H}=1\right.$ at time $\left.t=t_{H}\right)$ or when it dries out $\left(H=H_{\min }\right)$ (see Figure 5). Consider the case where $\mathrm{H}$ has not dried out. Then the first activation of the overflow triggers a pulse in the sensitivities $\mathcal{S}_{H_{0}}$ and $\mathcal{R}_{H_{0}}$ (see terms $X \partial Q_{\mathrm{H}} / \partial H_{0}$ and $(1-X) \partial Q_{\mathrm{H}} / \partial H_{0}$ in equations (A.3c) and (A.3d) respectively, and see Figure 4c). On the contrary, a complete emptying of the reservoir $\mathrm{H}$ before the first overflow completely stops the propagation of the sensitivity to $H_{0}$ towards the reservoirs $\mathrm{S}$ and $\mathrm{R}$. Also note that a simulation that begins with a low water period with no complete emptying of the reservoir $\mathrm{H}$ only delays the propagation of the sensitivity to $H_{0}$ within the model (see Figure $5 \mathrm{~b}$ ). Last, a complete emptying of the reservoir $\mathrm{H}$ after the first overflow has no impact on the propagation of the sensitivity to $H_{0}$.

Consider the case where the first activation of the overflow happens before the reservoir $\mathrm{H}$ dries out. If the threshold $S_{\text {sill }}$ is not activated, then for $t \geq t_{H}$ the sensitivities $\mathcal{S}_{H_{0}}$ and $\mathcal{R}_{H_{0}}$ decrease exponentially. The activation of the threshold $S_{\text {sill }}$ results in a decrease in $\mathcal{S}_{H_{0}}$ and in an increase in $\mathcal{R}_{H_{0}}$ (see Figure $4 \mathrm{c}$ ). 

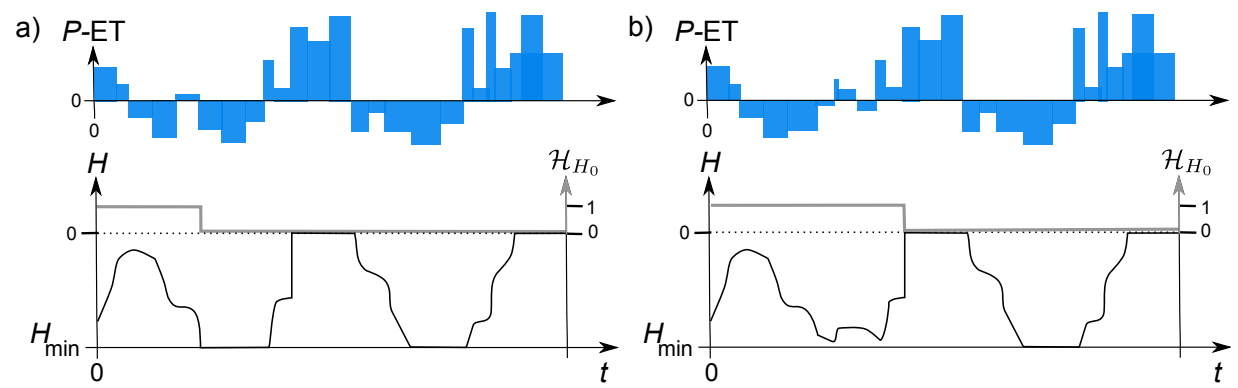

Figure 5: Vensim model. Typical behaviour of the sensitivities to the initial water level $H_{0}$ contingent on the activation or de-activation of the rapid tranfer function: a) complete emptying of the reservoir $\mathrm{H}$ before the first overflow, b) no emptying of the reservoir $\mathrm{H}$ before the first overflow.

\begin{tabular}{lll}
\hline Symbol & Meaning & Value \\
\hline$H_{\text {sec }}$ & threshold level for secondary spring activation & $145 \mathrm{~mm}$ \\
$k_{\text {sec }}$ & specific discharge coefficient for the secondary springs discharge function & $2.9 \times 10^{-2} / \mathrm{d}$ \\
$H_{1}$ & lower threshold level for the hysteretic discharge function & $100 \mathrm{~mm}$ \\
$H_{2}$ & upper threshold level for the hysteretic discharge function & $119 \mathrm{~mm}$ \\
$k_{\mathrm{HY}}$ & specific discharge coefficient for the hysteretic discharge function & $2 \times 10^{-2} \mathrm{~mm} / \mathrm{d}$ \\
$\alpha$ & exponent for the hysteretic discharge function & 2.4 \\
$k_{\mathrm{HL}}$ & specific discharge coefficient for the infiltration to the lower reservoir & $7 \times 10^{-3} / \mathrm{d}$ \\
$k_{\mathrm{L}}$ & specific discharge coefficient for the baseflow discharge & $4 \times 10^{-3} / \mathrm{d}$ \\
\hline
\end{tabular}

Table 2: Hysteresis-based model. Parameter set used in Section 4, 5.2 and 5.4.

\section{Computational examples}

The analysis of the sensitivity behaviour undertaken in Section 3 is valid regardless of the particular values assigned to the parameters. The following computational examples aim at illustrating some features of the sensitivity behaviour as a function of model structure. The sensitivity equations are solved numerically using an explicit Euler scheme. The parameter set used for the simulations is the one proposed by [7] (see parameters in Tables 4 and 2). For each example the simulation starts from a different time. The initial conditions are modified accordingly (see values in Tables 5 and 3 ).

\subsection{Computational example 1}

The first case tested is that of the time series used in [7]. The simulation starts on 1 January 2002. The internal water levels are presented in Figure 6.1. The initial state values were set as follows. A first simulation is run with arbitary initial states. Then, the average water storage over the simulation period is used as an initial value for the computational example

Consider the hysteresis-based model model. Figure 7 a shows the sensitivities to the initial water levels in the reservoirs $\mathrm{H}$ and L. The sensitivities $\mathcal{L}_{L o}$ and $\mathcal{Q}_{L o}$ decrease exponentially as stated in Section 3.2.1.

\begin{tabular}{clll}
\hline Example & Symbol & Meaning & Value \\
\hline \hline \multirow{2}{*}{1} & $H_{0}$ & initial water level in the reservoir H & $40 \mathrm{~mm}$ \\
& $L_{0}$ & initial water level in the reservoir L & $150 \mathrm{~mm}$ \\
\hline \multirow{2}{*}{2} & $H_{0}$ & initial water level in the reservoir H & $108 \mathrm{~mm}$ \\
& $L_{0}$ & initial water level in the reservoir L & $156 \mathrm{~mm}$ \\
\hline \multirow{2}{*}{3} & $H_{0}$ & initial water level in the reservoir H & $50 \mathrm{~mm}$ \\
& $L_{0}$ & initial water level in the reservoir L & $130 \mathrm{~mm}$ \\
\hline
\end{tabular}

Table 3: Hysteresis-based model. Initial conditions used in Section 4, 5.2 and 5.4. 

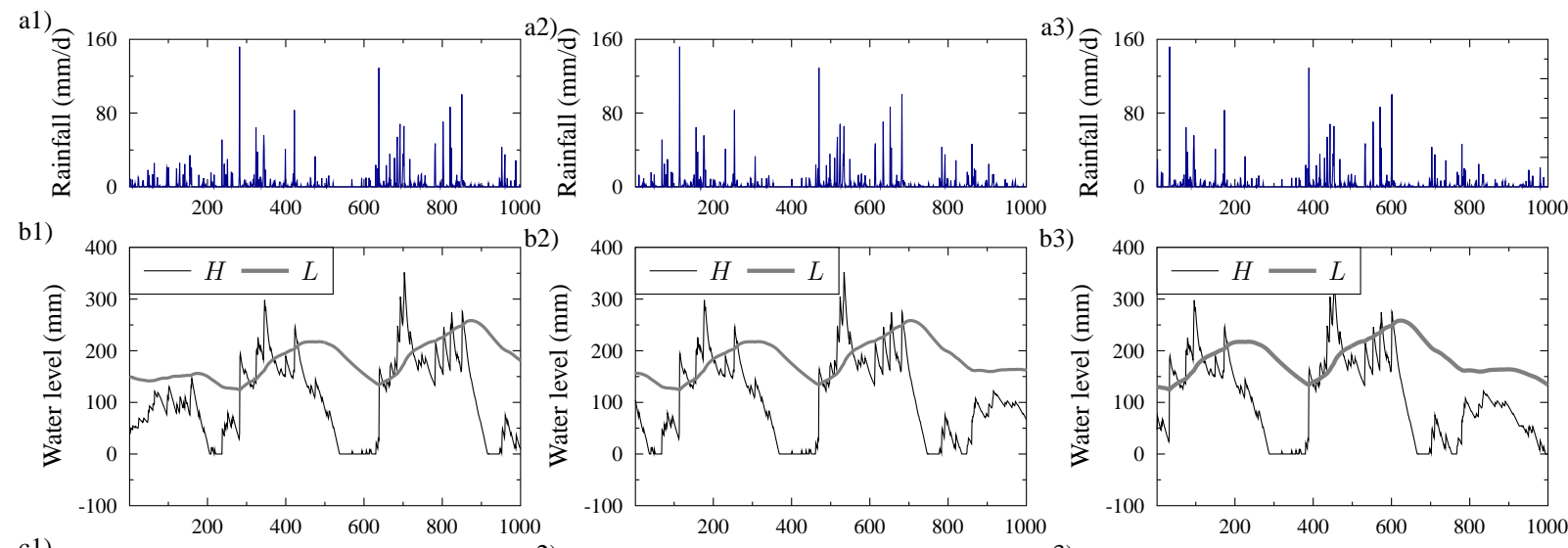

b3)
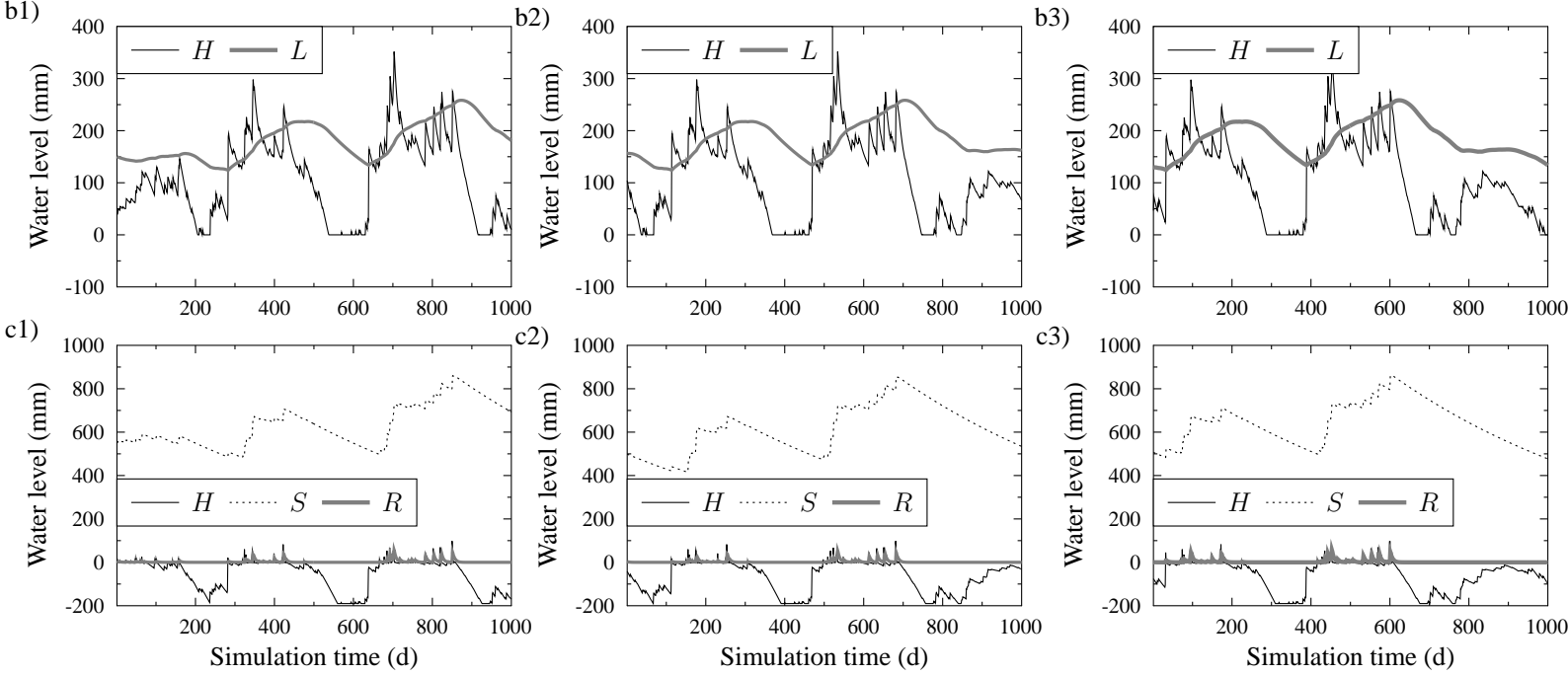

Figure 6: Daily rainfall (graphs a) and simulated water levels for the hysteresis-based (graphs b) and Vensim (graphs c) models for: the computational example 1 (graphs 1), the computational example 2 (graphs 2), the computational example 3 (graphs $3)$.

\begin{tabular}{lll}
\hline Symbol & Meaning & Value \\
\hline$H_{\min }$ & minimum water level admissible in the reservoir H & $-190 \mathrm{~mm}$ \\
$X_{\mathrm{D}}$ & distribution coefficient in low water level & 0.81 \\
$X_{\mathrm{W}}$ & distribution coefficient in high water level & 0.24 \\
$S_{\text {sill }}$ & threshold level for the switch in the distribution coefficient & $600 \mathrm{~mm}$ \\
$k_{\mathrm{S}}$ & specific discharge coefficient for the reservoir S discharge function & $1.5 \times 10^{-3} / \mathrm{d}$ \\
$k_{\mathrm{R}}$ & specific discharge coefficient for the reservoir R discharge function & $1.8 \times 10^{-1} / \mathrm{d}$ \\
\hline
\end{tabular}

Table 4: Vensim model. Parameter set used in Sections 4, 5.3 and 5.4

\begin{tabular}{clll}
\hline Example & Symbol & Meaning & Value \\
\hline \hline \multirow{2}{*}{1} & $H_{0}$ & initial water level in the reservoir H & $5 \mathrm{~mm}$ \\
& $S_{0}$ & initial water level in the reservoir S & $550 \mathrm{~mm}$ \\
& $R_{0}$ & initial water level in the reservoir R & $50 \mathrm{~mm}$ \\
\hline \multirow{3}{*}{2} & $H_{0}$ & initial water level in the reservoir H & $-35 \mathrm{~mm}$ \\
& $S_{0}$ & initial water level in the reservoir S & $500 \mathrm{~mm}$ \\
& $R_{0}$ & initial water level in the reservoir R & $0 \mathrm{~mm}$ \\
\hline \multirow{3}{*}{3} & $H_{0}$ & initial water level in the reservoir H & $-100 \mathrm{~mm}$ \\
& $S_{0}$ & initial water level in the reservoir S & $508 \mathrm{~mm}$ \\
& $R_{0}$ & initial water level in the reservoir R & $1 \mathrm{~mm}$ \\
\hline
\end{tabular}

Table 5: Vensim model. Initial conditions used in Sections 4, 5.3 and 5.4. 
a1)

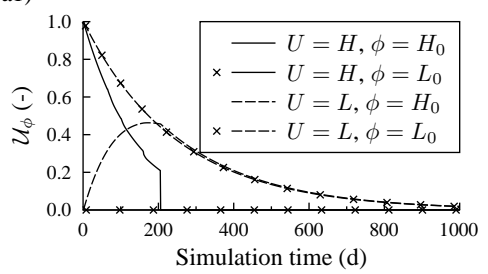

a2)

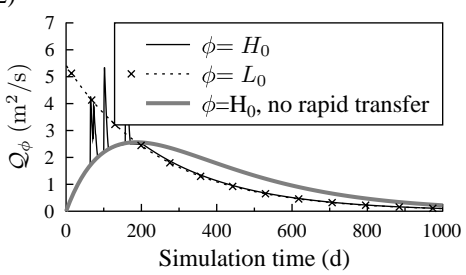

b1

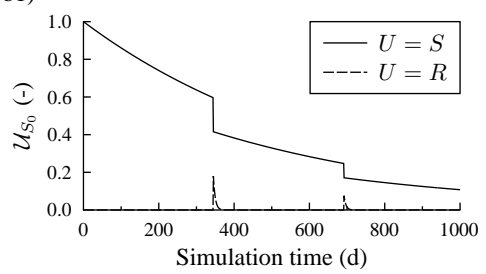

b2)

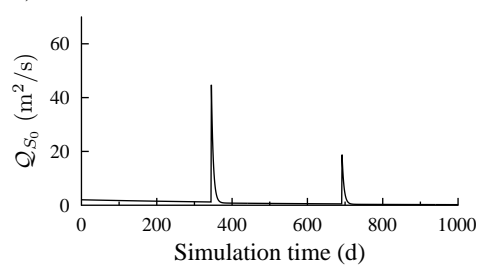

c1)

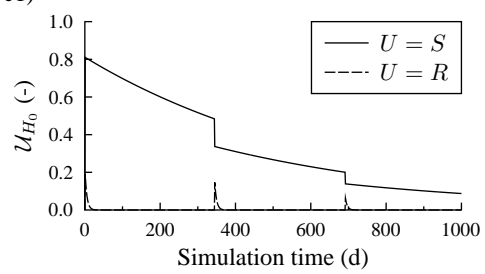

c2)

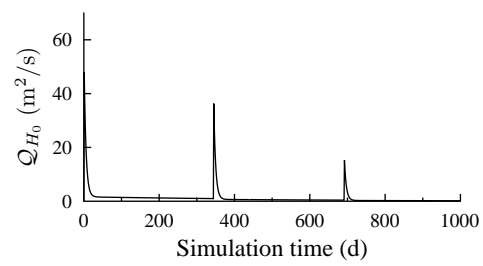

Figure 7: Computational example 1. Graphs a): hysteresis-based model. Sensitivity of the simulated water levels (graph 1) and of the simulated discharge (graph 2) to $H_{0}$ and $L_{0}$. Graphs b): Vensim model. Sensitivity of the simulated water levels (graph 1) and of the simulated discharge (graph 2) to $S_{0}$. Graphs c): Vensim model. Sensitivity of the simulated water levels (graph 1) and of the simulated discharge (graph 2) to $H_{0}$. The simulation parameters are given in Tables 2 and 4.

The activation of the hysteretic transfer on days 70, 110 and 160 results in a decrease of $\mathcal{H}_{H_{0}}$ and in an increase of $\mathcal{Q}_{H_{0}}$ as predicted in Section 3.2.2. Note that the magnitude of both the decrease in $\mathcal{H}_{H_{0}}$ and the increase in $\mathcal{Q}_{H_{0}}$ remains limited, which must be related to the fact that the rainfall remains low. The drying of reservoir $\mathrm{H}$ at day 205 results in a sudden drop of $\mathcal{H}_{H_{0}}$ and in a change in the derivatives of $\mathcal{L}_{H_{0}}$ and $\mathcal{Q}_{H_{0}}$.

Consider now the Vensim model. Figure 7b shows the sensitivities to the initial water level in the reservoir $\mathrm{S}$. Up to day 375 , the sensitivity of the water level in $\mathrm{R}$ to $S_{0}$ is equal to zero and the sensitivity of the water level in $\mathrm{S}$ to $S_{0}$ decreases exponentially. The activation of the switch in the distribution coefficient (activation of the threshold $S_{\text {sill }}$ ) at days 375 and 700 results in a sudden decrease in $\mathcal{S}_{S_{0}}$, and in a sudden increase in $\mathcal{R}_{S_{0}}$ as stated in Section 3.3. The increase in $\mathcal{R}_{S_{0}}$ triggers an increase in the discharge sensitivity $\mathcal{Q}_{S_{0}}$. Note that the de-activation of the threshold $S_{\text {sill }}$ at day 550 has no impact on the sensitivities behaviour, which confirms the analysis of Section 3.3.2. Figure 7c shows the sensitivities to the initial water level in the reservoir $\mathrm{H}$. The reservoir $\mathrm{H}$ is overflowing at the beginning of the simulation $\left(t_{H}=t_{0}\right)$. The sensitivities $\mathcal{S}_{H_{0}}$ and $\mathcal{R}_{H_{0}}$ decrease exponentially until the threshold $S_{\text {sill }}$ is activated. The activation of $S_{\text {sill }}$ results in a decrease in $\mathcal{S}_{H_{0}}$ and in an increase in $\mathcal{R}_{H_{0}}$ and $\mathcal{Q}_{H_{0}}$, as predicted in Section 3.3.3.

For both models, the maximum discharge sensitivity values are reached during the activation of the threshold transfer functions. As for the hysteresis-based model, the drying of the reservoir $\mathrm{H}$ during the warm-up year prevents the simulated discharge from any subsequent sensitivity burst. On the contrary , discharge sensitivity bursts for the Vensim model are triggered by any activation of the $S_{\text {sill }}$ threshold. Also note that the maximum discharge sensitivity values for the Vensim model are approximately one order of magnitude higher than those of the hysteresis-based model.

\subsection{Computational example 2}

The second computational example starts on 19 June 2002. The rainfall time serie starts with a low water period, followed by a heavy rainfall event. The internal water levels are presented in Figure 6.2. The initial internal state is taken equal to the internal state simulated in the computational example 1 by the start time of the simulation.

Consider the hysteresis-based model. Figure $8 \mathrm{a}$ shows the sensitivities to the initial water levels in the reservoirs $\mathrm{H}$ and $\mathrm{L}$ as a function of the simulation time. The sensitivities $\mathcal{L}_{L o}$ and $\mathcal{Q}_{L o}$ decrease exponentially. The complete emptying of the reservoir $\mathrm{H}$ at day 45 results in a brutal drop in the sensitivities to $H_{0}$.

Consider the Vensim model. Figure 8b shows the sensitivities to the initial water level in the reservoir S. The successive activations of the threshold $S_{\text {sill }}$ from day 190 to day 220 result in a strong decrease in 
a1)

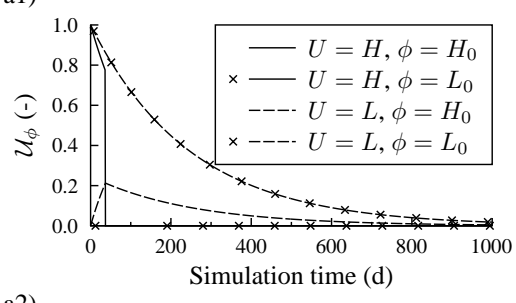

a2)

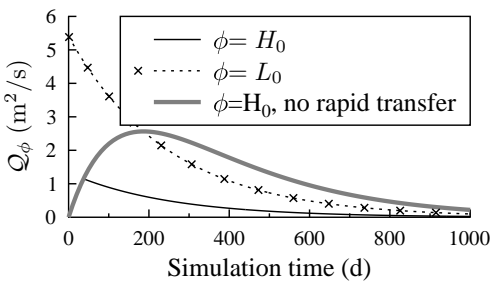

b1)

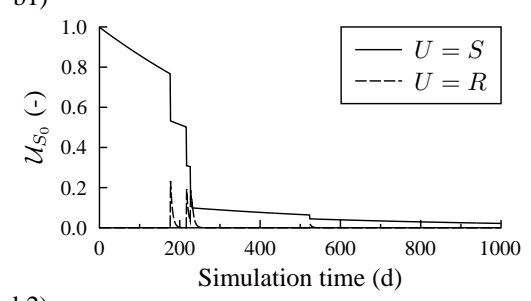

b2)

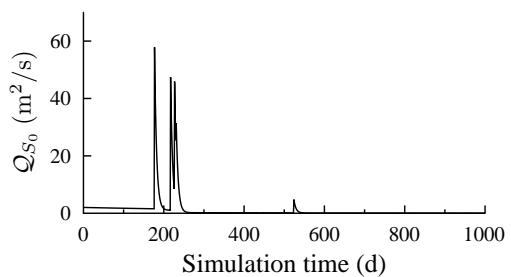

c1)

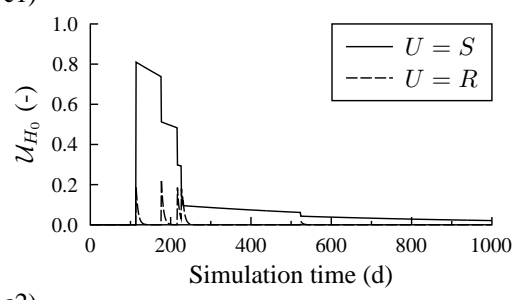

c2)

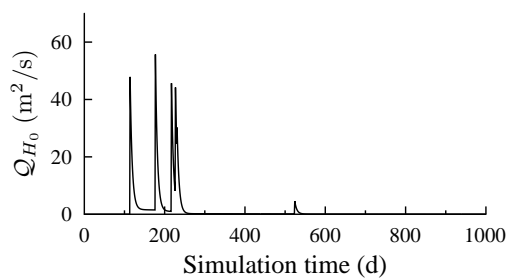

Figure 8: Computational example 2. Graphs a): hysteresis-based model. Sensitivity of the simulated water levels (graph 1) and of the simulated discharge (graph 2) to $H_{0}$ and $L_{0}$. Graphs b): Vensim model. Sensitivity of the simulated water levels (graph 1) and of the simulated discharge (graph 2) to $S_{0}$. Graphs c): Vensim model. Sensitivity of the simulated water levels (graph 1) and of the simulated discharge (graph 2) to $H_{0}$. The simulation parameters are given in Tables 2 and 4.

$\mathcal{S}_{S_{0}}$ as compared to simulation 1, but also in sensitivity bursts for the simulated water level in $\mathrm{R}$ and for the spring discharge $Q$. Figure $8 \mathrm{c}$ shows the sensitivities of the water levels and of the spring discharge to the initial water level in the reservoir $H$. The sensitivities to $H_{0}$ are equal to zero until the first overflow of the reservoir $H$ (day 110). The behaviour of the sensitivities to $H_{0}$ against the activations of the threshold $S_{\text {sill }}$ after the first overflow is similar to that of the sensitivities to $S_{0}$, as stated in Section 3.3.3.

The fact that the simulation begins with a low water period has different consequences for the Vensim and the hysteresis-based models. The low water period delays the propagation of the sensitivity to $H_{0}$ for the Vensim model. On the contrary, for the hysteresis-based model the sensitivity to $H_{0}$ leaks towards the lower reservoir and the simulated discharge from the beginning of the simulation on.

\subsection{Computational example 3}

The last computational example starts on 8 September 2002. The rainfall time serie starts with a drought period, which is followed by a heavy rainfall event. The internal water levels are presented in Figure 6.3. The initial internal state is taken equal to the internal state simulated in the computational example 1 by the start time of the simulation.

Consider the hysteresis-based model. Figure 9a shows the sensitivities to the initial water levels in the reservoirs $\mathrm{H}$ and $\mathrm{L}$ as a function of the simulation time. The sensitivities $\mathcal{L}_{L o}$ and $\mathcal{Q}_{L o}$ to the initial water level in L decrease exponentially as stated in Section 3.2.1. The activation of the hysteretic transfer from day 40 to day 100 results in a decrease of the sensitivity $\mathcal{H}_{H_{0}}$ and in an increase of the sensitivity $\mathcal{Q}_{H_{0}}$ as seen in Section 3.2.2. Note that the magnitude of both the decrease in $\mathcal{H}_{H_{0}}$ and the increase in $\mathcal{Q}_{H_{0}}$ is larger than in the computational example 1, which must be related to the importance of the rainfall events.

Consider the Vensim model. Figures $9 \mathrm{~b}$ and $9 \mathrm{c}$ show the sensitivities to the initial water level in the reservoirs $\mathrm{S}$ and $\mathrm{H}$ respectively. The sensitivities behaviour is similar to that observed in the example 1 . The sensitivity $\mathcal{S}_{S_{0}}$ decreases exponentially. The activation of the $S_{\text {sill }}$ results in a sudden decrease in $\mathcal{S}_{S_{0}}$, and in an increase in $\mathcal{R}_{S_{0}}$ and $\mathcal{Q}_{S_{0}}$. The sensitivities to $H_{0}$ are equal to zero until day 30 when the first overflow of the reservoir $\mathrm{H}$ occurs. The first overflow results in a burst in the sensitivities of $S, R$ and $Q$. After the first overflow, the behaviour of the sensitivities to $H_{0}$ is similar to that of the sensitivities to $S_{0}$.

This example illustrates the influence of a heavy rainfall period on sensitivity propagation. As for the hysteresis-based model, the activation of the hysteretic transfer due to intense rainfall results in a rapid decrease of the sensitivity to $H_{0}$. On the contrary, for the Vensim model the propagation of the sensitivity to $H_{0}$ and $S_{0}$ is independent from the magnitude of the rainfall event. 
a1)

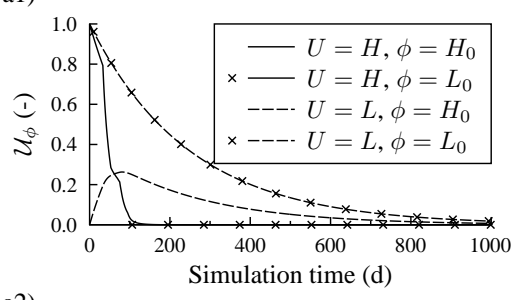

a2)

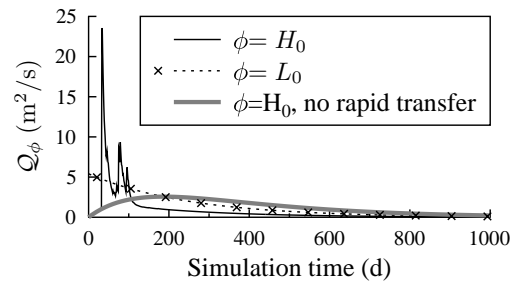

b1)

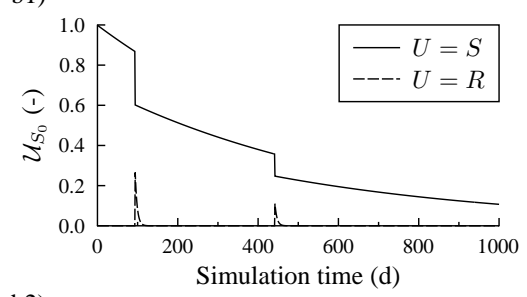

b2)

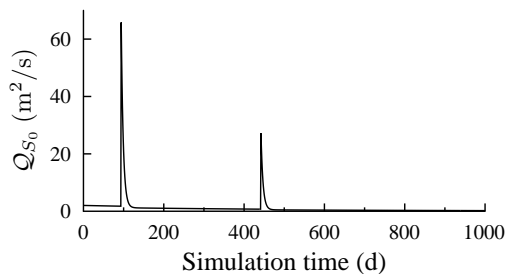

c1)

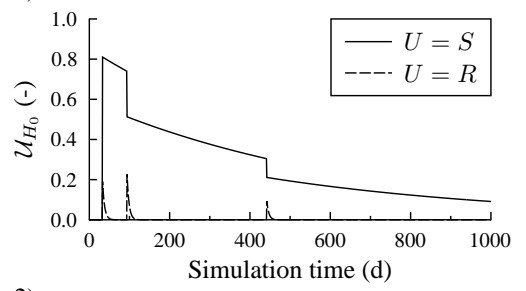

c2)

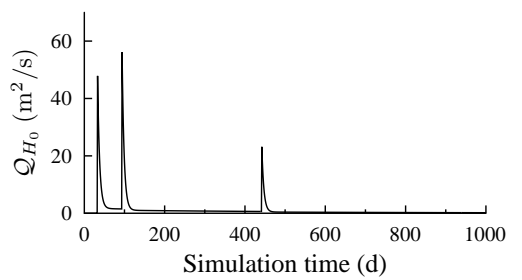

Figure 9: Computational example 3. Graphs a): hysteresis-based model. Sensitivity of the simulated water levels (graph 1) and of the simulated discharge (graph 2) to $H_{0}$ and $L_{0}$. Graphs b): Vensim model. Sensitivity of the simulated water levels (graph 1) and of the simulated discharge (graph 2) to $S_{0}$. Graphs c): Vensim model. Sensitivity of the simulated water levels (graph 1) and of the simulated discharge (graph 2) to $H_{0}$. The simulation parameters are given in Tables 2 and 4.

\section{Assessment of the appropriateness of the warm-up period}

The theoretical developments presented in Section 3 provide a qualitative understanding of the behaviour of the Vensim and hysteresis-based models in relation to their initialisation period. In practice, two questions may arise when working on a given model and meteorological input series:

(i) do the initial conditions have an influence on the calibration results?

(ii) do the initial conditions have an influence on the simulation results ?

These questions call for quantitative answers. Answering question (i) requires an estimation of the uncertainty on the calibration criterion. Answering question (ii) requires an estimation of the uncertainty on the simulated variable.

The aim of this Section is to assess the suitability of the local approach for answering question (i) for the Vensim and hysteresis-based models, based on the Durzon example. Both the warm-up and the calibration periods are assumed to be one-year-long, which is the duration used in [7]. The calibration is assumed to be based on the Nash criterion only, which is the procedure adopted by [7] and [10]. The Nash efficiency is the one of the most widely used measure of model performance. It is a normalized variant of the mean squared error criterion. The Nash criterion be interpreted as the sum of three indicators involving the correlation coefficient between the measured and modelled variable as well as a measure of conditional and unconditional bias $[21,22]$. An alternative decomposition involves the correlation, the bias and a measure of relative variability in the measured and modelled signals [23]. Theoretical justifications for its use in model performance assessment include the fact that the Nash optimum corresponds to the maximum likelihood estimator for a homoscedastic, gaussian distribution of model errors [20]. In practice, calibration is often based on a set of performance measures [24, e.g.] so that model performance is assessed against different aspect of the system response $[25,26]$. Note the main conclusions of the analysis presented below remain valid for other, distance-based measures of model performance.

Section 5.1 details the methodology for the estimation of the uncertainty on the performance criterion, based on the local perturbation approach. Numerical applications to the Vensim and hysteresis-based models are given in Sections 5.3 and 5.2. The validity of the local approach is checked in Section 5.4. The available warm-up period may sometimes be too short to allow for a proper elimination of the initialisation bias. In that case, an intuitive solution would consist in replicating the warm-up time series several times, so as to obtain a sufficiently long warm-up period. The suitability of this approach for the studied daily, non-linear models is assessed in Section 5.5. 


\subsection{Principle of local uncertainty estimation}

Denote by $\Delta \phi$ the uncertainty in the initial water level in the reservoir $\Phi(\Phi=\mathrm{H}, \mathrm{S}, \mathrm{L}$ or R$)$. The uncertainty $\Delta \mathcal{Q}_{\phi(t)}$ in the discharge estimate at time $t$ may be approximated to the first order by

$$
\Delta \mathcal{Q}_{\phi(t)} \equiv \mathcal{Q}_{\phi(t)} \Delta \phi
$$

where $\mathcal{Q}_{\phi(t)}$ denotes the sensitivity of the simulated spring discharge to the parameter $\phi$ at time $t$. The value of $\mathcal{Q}_{\phi(t)}$ can be obtained by solving numerically the sensitivity equations as done in Section 4 .

Similarly, the bias $\Delta \mathcal{N}_{\phi}$ in the Nash efficiency may be approximated to the first order by

$$
\Delta \mathcal{N}_{\phi} \equiv \mathcal{N}_{\phi} \Delta \phi
$$

where $\mathcal{N}_{\phi}$ denotes the sensitivity of the Nash criterion to the initial water level $\phi$ in the reservoir $\Phi$. The Nash criterion may be expressed as

$$
N=1-\frac{\int_{t_{1}}^{t_{2}}\left(Q-Q_{\mathrm{obs}}\right)^{2} d t}{\int_{t_{1}}^{t_{2}}\left(Q_{\mathrm{obs}}-\overline{Q_{\mathrm{obs}}}\right)^{2} d t}
$$

where $t_{1}$ and $t_{2}$ are the initial and final times for the calibration period, $Q_{\mathrm{obs}}$ is the spring discharge measured at time $t$ and $\overline{Q_{\text {obs }}}$ is the mean measured spring discharge during the calibration period. Differentiating equation (21) with respect to parameter $\phi$ leads to

$$
\mathcal{N}_{\phi}=-2 \int_{t_{1}}^{t_{2}} Q^{*} \mathcal{Q}_{\phi} d t
$$

where

$$
Q^{*}=\frac{Q-Q_{\mathrm{obs}}}{\int_{t_{1}}^{t_{2}}\left(Q_{\mathrm{obs}}-\overline{Q_{\mathrm{obs}}}\right)^{2} d t}
$$

Equation (19) can therefore be recast into

$$
\Delta \mathcal{N}_{\phi} \equiv \int_{t_{1}}^{t_{2}} J_{\phi} d t
$$

where

$$
J_{\phi}=-2 Q^{*} \Delta \mathcal{Q}_{\phi}
$$

\subsection{Case of the hysteresis-based model}

Similarly, the uncertainty on the simulated spring discharge can be estimated for a $25 \%$ variation in $H_{0}$ or $L_{0}$ (see Figure 10a). The uncertainty in the discharge estimate is larger for a perturbation in $S_{0}$ than for a perturbation in $H_{0}$, which is due to the difference in the sensitivities $\left(\left|\mathcal{Q}_{S_{0}}\right|>\left|\mathcal{Q}_{H_{0}}\right|\right.$ based on Section 4). Note that unlike the case of the Vensim model, the maximum uncertainty in the discharge estimate during the calibration period (days 366 to 731) is reached at the beginning of the calibration period (no sensitivity burst). Indeed, for the three computational examples the reservoir $\mathrm{H}$ dried out before day 366 . The consequence of the complete emptying of the reservoir $\mathrm{H}$ is that subsequent activations of the rapid transfert function have no impact on the sensitivity value (see Section 3.2). The maximum uncertainty in the discharge estimate is approximately $\Delta \mathcal{Q}_{S_{0}}=0.05 \mathrm{~m}^{3} / \mathrm{s}$, to be compared to the average low water spring discharge $Q \simeq 0.6 \mathrm{~m}^{3} / \mathrm{s}$.

The efficiency bias over the calibration period can be estimated based on equation (25) (see numerical estimates in Table 6). Note that $\Delta \mathcal{N}$ is a function of both the discharge sensitivity and the discharge error (see equation (22a)). The maximum efficiency bias is $\Delta \mathcal{N}=2 \times 10^{-3}$ regardless of the parameter considered, which makes an influence of the initial condition on calibration unlikely. 


\begin{tabular}{|c|c|c|c|c|}
\hline Model & Example $n^{\circ}$ & Parameter & $\Delta \mathcal{Q}_{\phi(t=366)}\left(\mathrm{m}^{3} / \mathrm{s}\right)$ & $\Delta \mathcal{N}_{\phi}(\%)$ \\
\hline \multirow{6}{*}{ 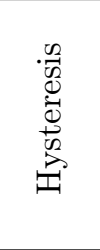 } & \multirow{2}{*}{1} & $H_{0}$ & $1.3 \times 10^{-2}$ & $4.8 \times 10^{-2}$ \\
\hline & & $L_{0}$ & $4.7 \times 10^{-2}$ & $1.7 \times 10^{-1}$ \\
\hline & \multirow{2}{*}{2} & $H_{0}$ & $8.3 \times 10^{-3}$ & $6.0 \times 10^{-3}$ \\
\hline & & $L_{0}$ & $4.9 \times 10^{-2}$ & $3.5 \times 10^{-2}$ \\
\hline & \multirow{2}{*}{3} & $H_{0}$ & $6.0 \times 10^{-3}$ & $1.9 \times 10^{-2}$ \\
\hline & & $L_{0}$ & $4.1 \times 10^{-2}$ & $1.3 \times 10^{-1}$ \\
\hline \multirow{6}{*}{ 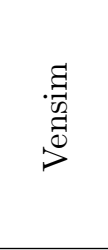 } & \multirow{2}{*}{1} & $H_{0}$ & $1.5 \times 10^{-3}$ & $4.3 \times 10^{-2}$ \\
\hline & & $S_{0}$ & $2.1 \times 10^{-1}$ & 5.9 \\
\hline & \multirow{2}{*}{2} & $H_{0}$ & $1.4 \times 10^{-3}$ & $2.3 \times 10^{-2}$ \\
\hline & & $S_{0}$ & $2.0 \times 10^{-2}$ & $3.4 \times 10^{-1}$ \\
\hline & \multirow{2}{*}{3} & $H_{0}$ & $1.7 \times 10^{-2}$ & $7.8 \times 10^{-1}$ \\
\hline & & $S_{0}$ & $1.0 \times 10^{-1}$ & 4.6 \\
\hline
\end{tabular}

Table 6: Hysteresis-based and Vensim models. Local estimates of the uncertainty in the simulated spring discharge at day 366 and of the bias in the Nash coefficient over the calibration period (days 366 to 731 ), assuming a $25 \%$ uncertainty in the initial water level $\phi$.

\subsection{Case of the Vensim model}

Assume a relative uncertainty of $25 \%$ on the estimation of $H_{0}$ (resp. $S_{0}$ ). The uncertainty on the simulated spring discharge can be estimated based on equation (19) (see Figure 10b). The uncertainty in the discharge estimate is one to two orders of magnitude higher for a perturbation in $S_{0}$ than for a perturbation in $H_{0}$, which is due to the difference in the order of magnitude of the absolute value of the perturbation $\left(\left|S_{0}\right|>\left|H_{0}\right|\right)$. The uncertainty in the discharge estimate at the begining of the calibration period (day 366) is the largest for example 3 (see Table 6), which must be related to the magnitude of the absolute value of the perturbation and also to the relatively low number of activations of the threshold $S_{\text {sill }}$ in the corresponding simulation. Note that for computational examples 1 and 3, the maximum uncertainty in the discharge estimate during the calibration period (days 366 to 731 ) is reached at days 700 and 450 respectively, by the time of the activation of the switch in the distribution coefficient. The maximum uncertainty in the discharge estimate is approximately $\Delta \mathcal{Q}_{S_{0}}=2.5 \mathrm{~m}^{3} / \mathrm{s}$, to be compared to the corresponding spring discharge $Q \simeq 18 \mathrm{~m}^{3} / \mathrm{s}$. The activation of the switch in the distribution coefficient may hence hinder the estimation of the flood peaks discharges.

Similarly, the efficiency bias $\Delta \mathcal{N}$ over the calibration period can be estimated from equation (25) (see numerical estimates in Table 6 ). Note that $\Delta \mathcal{N}$ is a function of both the discharge sensitivity and the discharge error (see equation (22a)). The maximum bias in the Nash efficiency is $\Delta \mathcal{N}_{H_{0}}=8 \times 10^{-3}$ for a perturbation in $H_{0}$ (computational example 3 ) and $\Delta \mathcal{N}_{S_{0}}=6 \times 10^{-2}$ for a perturbation in $S_{0}$ (computational example 1). An inaccurate estimate of the initial water level in the reservoir $S$ may therefore have an impact on the calibration results.

Equation (22a) suggests that two options can be considered in order to reduce the efficiency bias

1. extend the calibration period. Indeed, at large time the discharge sensitivity $\mathcal{Q}_{\phi}$ tends to zero, which means that the numerator of equation (22a) tends to a finite value. On the other hand, the denominator of (22a) is approximately proportional to the length $t_{2}-t_{1}$ of the calibration period. As a consequence, for very large calibration periods the efficiency bias tends to zero.

2. extend the warm-up period. Indeed, the efficiency bias $\Delta \mathcal{N}_{\phi}$ is all the more reduced as the discharge sensitivity $\mathcal{Q}_{\phi}$ is low.

\subsection{Validity of the local uncertainty estimates}

The range of validity of the local sensitivity and uncertainty analyses is restricted to "small" perturbations in the values of the parameters, the meaning of "small" being dependent upon the degree of non-linearity of the model, and possibly the nominal value used for the analysis. The validity of the local sensitivity 

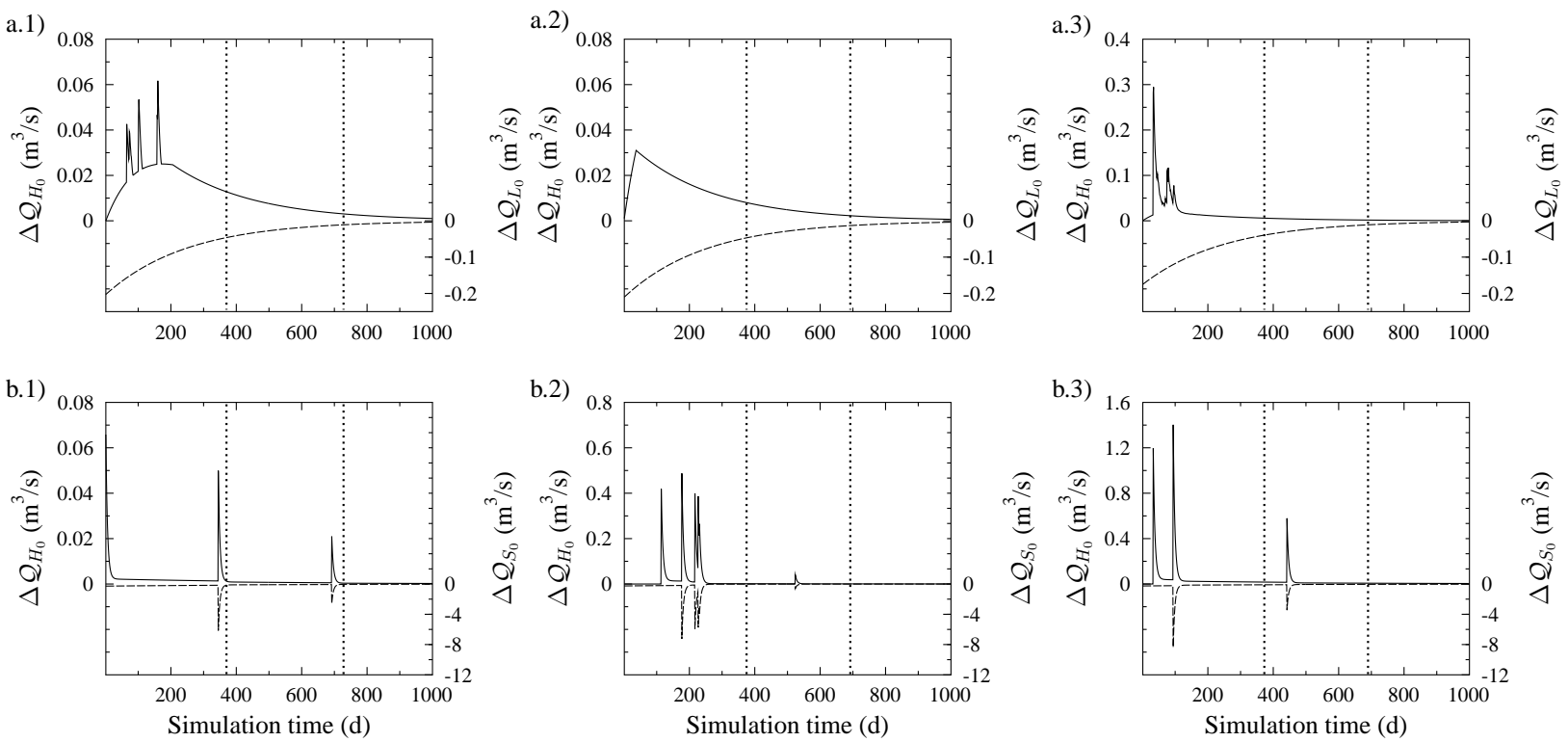

Figure 10: Local uncertainty $\Delta \mathcal{Q}$ in the discharge estimate for the hysteresis-based and Vensim models. Hysteresis-based model (graphs a): case of a $25 \%$ perturbation in the initial $H_{0}$ (left $y$-axis, solid line) and $L_{0}$ (right $y$-axis, dotted line) estimates. Vensim model (graphs b): case of a $25 \%$ perturbation in the initial $H_{0}$ (left $y$-axis, solid line) and $S_{0}$ (right $y$-axis, dotted line) estimates. The uncertainty estimates are calculated for the computational examples 1 (graphs a1 and b1), 2 (graphs a2 and b2) and 3 (graphs a3 and b3). The beginning and the final time for the calibration period are indicated by vertical, dotted lines.

and uncertainty estimates is checked by comparison against empirical estimates in Appendix C. The linear approximation is found to be valid for the hysteresis-based model for perturbations up to $50 \%$ of the nominal value of the perturbed parameter. On the other hand, for the Vensim model the linear approximation fails for perturbations as small as $10 \%$ of the nominal value of the parameter perturbed. The difference in the range of validity of the linear approximation is due to the difference in the degree of nonlinearity in the two models.

\subsection{Compensating the lack of data with a repetition of available time series}

The available warm-up period may sometimes be too short to allow for a proper elimination of the initialisation bias. An intuitive solution would consist in replicating the input time series of the warm-up period several times, so as to obtain a sufficiently long warm-up period. These replicated time series would be inserted before the current warm-up period in the input time series of the model (see Figure 11a-b). For this reason, the newly extended time series is termed a "pre-warm-up period". Since this artificially reconstructed pre-warm-up time series is not necessarily representative of the actual forcings that occured over the pre-warm-up period, it is not certain at all that this practice would allow the initialisation bias to be eliminated. The purpose of the present subsection is to investigate whether it is actually the case.

Consider the time series used in the computational example 1 (Section 4.1) for the Vensim model. Assume that the available meteorological data record starts on day 731. The data record is extended artificially back to day 1 with the data recorded on days 731 to 1461 (see Figure 11a,b). The period day 1 - day 730 is used to produce an initial state estimate for the internal variables of the model which is hoped to be more realistic than the modeller's best guess (pre-warming up period). This initial state estimate can be compared to the state reached by running the model for the true meteorological data record (see Figure 11c). The difference in the initial state estimates at day 731 for the actual and extended record data is negligible for the reservoirs $\mathrm{H}$ and R. However, the difference in the $S$ estimate is $38 \%$ of the $S$ value for the actual record. The repetition of the available data record may thus not suffice to eliminate the bias due to the initialisation uncertainty. 

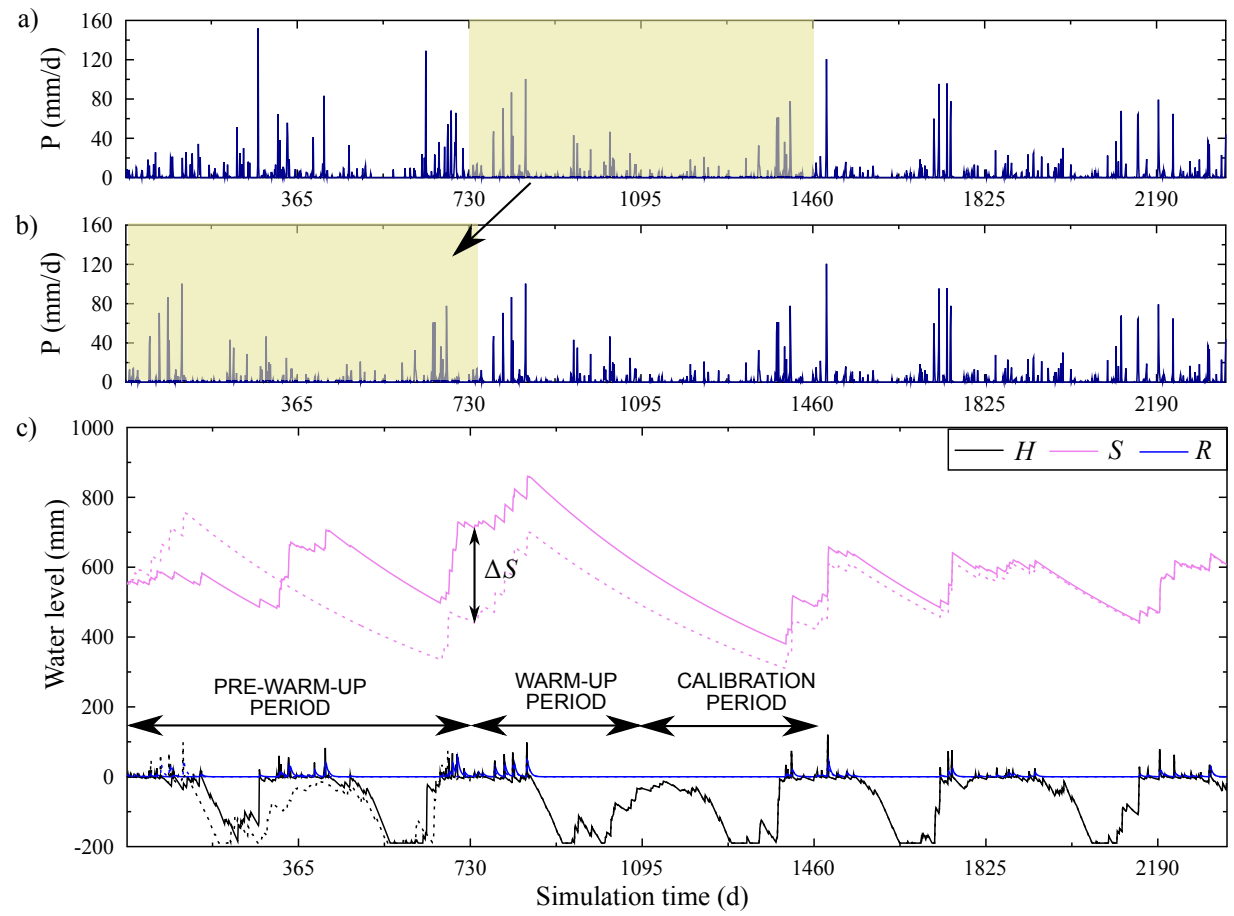

Figure 11: Initial estimate of state variables. a) actual meteorological record, b) extended meteorological record, c) water level in the reservoir $\mathrm{H}, \mathrm{S}$ and $\mathrm{R}$ for a simulation using the actual (solid lines) or extended (dotted lines) meteorological record.

\section{Discussion}

This Section is a summary and interpretation of the results obtained in Sections 3 to 5 .

\subsection{Sensitivity to the initial water level in the lower reservoirs}

The functioning of the reservoir $\mathrm{L}$ of the hysteresis-based model and that of the reservoir $\mathrm{R}$ of the Vensim model is linear. Indeed, the emptying of these reservoirs is modeled by a linear discharge relationship and the water level in these reservoirs does not trigger any change in the model functioning (no associated threshold transfer function). As a consequence, the sensitivity to the initial water levels $\left(L_{0}\right.$ or $\left.R_{0}\right)$ is controlled by the only specific discharge coefficient $k_{\Phi}$ of the reservoir $\Phi$ considered $(\Phi=\mathrm{L}, \mathrm{R})$. The sensitivity decreases exponentially, with a time constant $T=1 / k_{\Phi}$

1. in the case of the hysteresis-based model, the reservoir L accounts for baseflow discharge, which means that the numerical value of the specific discharge coefficient $k_{L}$ is low. As a consequence, the discharge sensitivity to $L_{0}$ is relatively low, but it decreases slowly,

2. in the case of the Vensim model, the reservoir R accounts for rapid infiltration towards the outlet, which means that the numerical value of the specific discharge coefficient $k_{\mathrm{R}}$ is high. As a consequence, the discharge sensitivity to $R_{0}$ is high, but it decreases rapidly.

The emptying of the reservoir $\mathrm{S}$ of the Vensim model is modelled by a linear discharge relationship. The difference with the reservoirs $\mathrm{R}$ and $\mathrm{L}$ lies in the fact that the water level in the reservoir $\mathrm{S}$ has an influence on model functioning. Indeed, the distribution coefficient $X$ of the upper reservoir overflow discharge $Q_{\mathrm{H}}$ is defined as $X=X_{\mathrm{D}}$ if $S \leq S_{\text {sill }}$ and $X=X_{\mathrm{W}}$ if $S>S_{\text {sill }}$ (see Section 2.3). The activation of the threshold $S_{\text {sill }}$ heavily affects the behaviour of the sensitivity to the initial water level $S_{0}$ (see Figure 4b)

1. assume that the threshold $S_{\text {sill }}$ is not activated. Then the sensitivity to $S_{0}$ decreases exponentially, with a time constant $T=1 / k_{\mathrm{S}}$. Since the reservoir $\mathrm{S}$ accounts for long-term storage within the karst 
aquifer, the specific discharge coefficient $k_{\mathrm{S}}$ associated with the linear discharge relationship is small. As a consequence, the decrease of the sensitivity to $S_{0}$ is slow (large time constant), but the numerical value of the sensitivity of the simulated spring discharge is small.

2. the activation of the threshold $S_{\text {sill }}$ triggers the leaks of part of the sensitivity to $S_{0}$ towards the reservoir R. The sensitivity of $S$ to $S_{0}$ decreases suddenly, while the sensitivity of $R$ to $S_{0}$ increases. This sensitivity peak is rapidly drained off the reservoir $\mathrm{R}$ (high specific discharge coefficient $k_{\mathrm{R}}$ ), which results in a sensitivity peak in the simulated discharge (see Figure 4b).

3. each activation of the threshold $S_{\text {sill }}$ therefore results in a sensitivity peak of the simulated discharge to $S_{0}$. The magnitude of the peak is proportional to the overflow discharge $Q_{\mathrm{H}}$ and to the remaining sensitivity of $S$ to $S_{0}$. Since the decrease of the sensitivity of $S$ to $S_{0}$ is slow, discharge sensitivity peaks of significant magnitude may occur years after the begining of the simulation. Also note that the number, magnitude and time of occurence of these sensitivity peaks is difficult to predict since they are linked to internal model variables (water level in the reservoir $\mathrm{S}$ and residual sensitivity of $S$ to $\left.S_{0}\right)$.

\subsection{Sensitivity to the initial water level in the upper reservoirs}

During low water periods the upper reservoir of the hysteresis-based model leaks towards the lower reservoir. By contrast, the upper reservoir of the Vensim model is disconnected from the lower reservoirs. For both models, a rapid emptying function is activated during high water periods

1. in the case of the hysteresis-based model, the propagation of the sensitivity to $H_{0}$ towards the lower reservoir starts at the beginning of the simulation. The activation of the rapid transfer functions results in a sudden decrease of the sensitivity to $H_{0}$, since part of the sensitivity to $H_{0}$ leaks directly towards the outlet (via the hysteretic transfer function) or is removed from the model (via the secondary springs transfer function). The consequence is a burst in the discharge sensitivity to $H_{0}$, the magnitude of which is proportional to the remaining sensitivity of $H$,

2. in the case of the Vensim model, the propagation of the sensitivity to $H_{0}$ into the model only begins with the activation of the overflow discharge (see Figure 5). The first activation of the overflow discharge triggers a Dirac peak in the sensitivity of the water level $\mathrm{H}$ to $H_{0}$, the magnitude of which is independant from the magnitude of the overflow discharge. The sensitivity to $H_{0}$ leaks entirely towards the lower reservoirs. Subsequent activations of the overflow discharge have no effect on the propagation of the sensitivity to $H_{0}$. The propagation of the sensitivity to $H_{0}$ in the reservoirs $\mathrm{S}$ and $\mathrm{R}$ is similar to that of the sensitivity to $S_{0}$ and $R_{0}$ respectively (see Figure $4 \mathrm{c}$ ).

As the upper reservoirs are affected by evapotranspiration, a complete emptying of these reservoirs is possible. The complete emptying of the reservoir $H$ causes the sensitivity of $H$ to $H_{0}$ to cancel.

1. In the case of the hysteresis-based model, part of the sensitivity to $H_{0}$ leaks towards the lower reservoir even during low flow periods. A complete emptying of the reservoir $\mathrm{H}$ therefore stops the propagation of the sensitivity towards the lower reservoir,

2. In the case of the Vensim model, the upper and lower reservoirs are disconnected during low water periods. As a consequence, a complete emptying of the reservoir $\mathrm{H}$ before the first overflow stops the propagation of the sensitivity to $H_{0}$ into the lower reservoirs. On the other hand, a low water period that does not result in a complete emptying of the reservoir only delays the propagation of the sensitivity. Lastly, a complete emptying of the reservoir $\mathrm{H}$ after the first overflow has no impact on the sensitivity propagation.

\section{Conclusion - practical recommandations}

\subsection{General rules for the initialisation bias behaviour}

The theoretical considerations and the application examples presented in Sections 3 to 5 and discussed in Section 6 have evidenced the role of model structure in the behaviour of the sensitivity to the initial conditions. As a broad rule, the dissipation of the sensitivity is favoured by 
1. very low water periods. Indeed, the drying of the upper reservoir completely stops the propagation of the sensitivity to the initial water level in the upper reservoir,

2. very high water periods. Indeed, the activation of the rapid transfer functions (i.e., threshold functions) in a given reservoir speeds up the propagation of the sensitivity to the initial water level in that reservoir.

The above-mentioned considerations must be adjusted according to the structure of the reservoirs considered.

1. Consider the case where leaks occur from the upper reservoir $\mathrm{H}$ towards the lower reservoirs whatever the water level in $\mathrm{H}$ (no threshold). Then the sensitivity to the initial water level in $\mathrm{H}$ leaks towards the lower reservoirs starting from the beginning of the simulation on. The drying of the upper reservoir therefore leads to the dissipation of a proportion of the sensitivity all the more important as the drying occurs rapidly after the beginning of the simulation. Such a behaviour is illustrated by the computational example 2 for the hysteresis-based model (see Figure 4.2b).

2. Consider the case where a rapid transfer function from a given reservoir is activated above a given threshold. Assume that the transfer function is all-or-nothing (e.g. transfer function $Q_{\mathrm{H}}$ from the reservoir $\mathrm{H}$ of the Vensim model). Then a single activation of that rapid transfer function triggers the propagation of all the sensitivity to the initial water level in that reservoir towards the other reservoirs or towards the outlet of the model (see Figure 5 for an illustration of that property for the Vensim model). Now, assume that the rapid transfer functions are not all-or-nothing (e.g. transfer function $Q_{\mathrm{HY}}$ from the reservoir $\mathrm{H}$ of the hysteresis-based model ). Then the propagation of the sensitivity becomes faster as the transfer functions are activated frequently and associated with high discharges. In other words, the propagation of the sensitivity is sped if the meteorological time serie includes numerous heavy rainfall events. Such a behaviour is illustrated by the computational example 3 for the hysteresis-based model (Figure 4.3b).

Conversely, the propagation of the sensitivity is impaired in the following situations

1. if the upper reservoir is disconnected from the lower reservoirs during the low water period, and the simulation begins with a low water period that does not results in a complete emptying of the upper reservoir. Indeed, the propagation of the sensitivity is delayed until the first activation of the transfer functions towards the lower reservoirs. Such a behaviour is illustrated by Figure 4c for the Vensim model.

2. if a threshold transfer function is associated to the water level in a reservoir with slow dynamics. Indeed, sensitivity bursts associated with the activation of the threshold transfer function may occur years after the simulation start. Such a behaviour is illustrated by the computational example 1 (Figure 7b,c) for the Vensim model.

The sensitivity to the initial water level in a lower, linear reservoir is controlled by the only specific discharge coefficient $k$ associated with the reservoir linear discharge relationship. Indeed, the sensitivity $\mathcal{Q}$ of the simulated discharge to the initial water level in that reservoir is $\mathcal{Q}=k A \exp (-k t)$ where $A$ is the total catchment area and $t$ is the simulation time. The sensitivity decreases exponentially with a time constant $T=1 / k$. The initial water level in a linear reservoir with a low discharge coefficient therefore has a relatively mild influence on the simulated discharge, but its influence decreases slowly (large time constant). On the other hand, the initial water level in a linear reservoir with a high discharge coefficient has a relatively high influence on the simulated discharge but its influence decreases slowly.

\subsection{Consequences for the modelling practice}

As regards the modelling practice, the main results of this study can be summarized as follows.

1. Threshold-based transfer functions generate Dirac sensitivity patterns. When associated with longterm memory reservoir and fast discharge models, they may generate a substantial initialisation bias even after very long periods of inactivity.

2. As a consequence of the above remark, the commonly-used one-year warm-up period may not ensure a proper elimination of the initialisation bias. 
3. When the available warm-up period is too short to allow for a proper elimination of the initialisation bias, an intuitive approach would consist in artificially extending the warm-up time series by replicating it several times. However, the artificially extended warm-up time series may not be representative of the actual forcings. As regards the present study, such a procedure proved inefficient to reduce the initialisation bias.

4. This work stresses the fact that the specification of the initial state may significantly bias the calibration step. This initialisation bias issue is little regarded in most practical applications. A careful examination of the initialisation bias behaviour should be part of the good modelling practices. In particular, the use of elaborate procedures for locating the global optimum of the objective function used for parameter optimization can only be justified in so far as the initialisation bias has been efficiently eliminated.

5. Local sensitivity analysis can be used as a low-computational cost tool to identify the main characteristics of the bias behaviour, even for conceptual models with strongly non-linear transfer functions.

6. The last remark is specific to the modelling of karst spring discharge. Recent studies have emphasized the need to account for the influence of the karst flowpath network connectivity on the system response dynamics [10, 7, 27]. The change in connectivity may be accounted for in the model structure by a threshold function, the activation of which depends on the water level in a given reservoir. As for the Vensim model, the threshold function triggers the switch in the distribution coefficient based on the water level in the lower, slow discharge reservoir. As regards the hysteresis-based model, the threshold function triggers the activation of the hysteretic transfer, based on the water level in the upper reservoir. Our study indicates that whenever possible, the activation of the threshold function should not be associated with the water level in a slow dynamics reservoir.

\section{Acknowledgements}

This work was supported by a $\mathrm{PhD}$ grant from the French Ministère de l'Éducation Nationale et de la Recherche (Allocation Couplée number 30368-2008). The authors wish to thank the "Parc naturel régional des Grands Causses" for the discharge data monitored at the Duzon spring and Météo France for the rainfall data recorded at the "Le Caylar" meteorological station.

\section{Appendix A. Sensitivity equations}

\section{Appendix A.1. Sensitivity equations for the hysteresis-based model}

Denote by $\mathcal{H}_{\phi}$ and $\mathcal{L}_{\phi}$ the sensitivities of the water levels in the reservoirs $\mathrm{H}$ and L to the parameter $\phi$. Applying the perturbation approach to the model equations (2) and (7) for a perturbation in $\phi=H_{0}$ leads 
to the following set of sensitivity equations

$$
\begin{aligned}
\frac{d \mathcal{H}_{H_{0}}}{d t} & =-\mathcal{H}_{H_{0}}\left[k_{\mathrm{sec}}\left(\varepsilon_{\mathrm{sec}}+\frac{\partial \varepsilon_{\mathrm{sec}}}{\partial H}\left(H-H_{\mathrm{sec}}\right)\right)+k_{\mathrm{HY}}\left(\frac{\partial \varepsilon_{\mathrm{HY}}}{\partial H}+\varepsilon_{\mathrm{HY}} \frac{\alpha}{H-H_{1}}\right)\left(\frac{H-H_{1}}{H_{2}-H_{1}}\right)^{\alpha}+k_{\mathrm{HL}}\right] \text { for } H>0 \\
\mathcal{H}_{H_{0}} & =0 \\
\frac{d \mathcal{L}_{H_{0}}}{d t} & =k_{\mathrm{HL}} \mathcal{H}_{H_{0}}-k_{L} \mathcal{L}_{H_{0}} \\
\mathcal{Q}_{H_{0}} & =k_{\mathrm{HY}} A \mathcal{H}_{H_{0}}\left(\frac{\partial \varepsilon_{\mathrm{HY}}}{\partial H}+\varepsilon_{\mathrm{HY}} \frac{\alpha}{H-H_{1}}\right)\left(\frac{H-H_{1}}{H_{2}-H_{1}}\right)^{\alpha}+k_{L} A \mathcal{L}_{H_{0}} \\
\mathcal{H}_{H_{0}}(t=0) & =1 \\
\mathcal{L}_{H_{0}}(t=0) & =0 \\
\mathcal{Q}_{H_{0}}(t=0) & =A \varepsilon_{\mathrm{HY}} k_{\mathrm{HY}} \frac{\alpha}{H_{2}-H_{1}}\left(\frac{H(t=0)-H_{1}}{H_{2}-H_{1}}\right)^{\alpha-1}
\end{aligned}
$$$$
\mathcal{L}_{H_{0}}(t=0)=0
$$

Similarly, applying equations the perturbation appraoch to the model equations (2) and (7) for a perturbation in $\phi=L_{0}$ leads to

$$
\begin{aligned}
\frac{d \mathcal{H}_{L_{0}}}{d t} & =0 \\
\frac{d \mathcal{L}_{L_{0}}}{d t} & =-k_{L} \mathcal{L}_{L_{0}} \\
\mathcal{Q}_{L_{0}} & =A\left[\varepsilon_{\mathrm{HY}} k_{\mathrm{HY}} \frac{\alpha \mathcal{H}_{L_{0}}}{H_{2}-H_{1}}\left(\frac{H-H_{1}}{H_{2}-H_{1}}\right)^{\alpha-1}+k_{L} \mathcal{L}_{L_{0}}\right] \\
\mathcal{H}_{L_{0}}(t=0) & =0 \\
\mathcal{L}_{L_{0}}(t=0) & =1 \\
\mathcal{Q}_{L_{0}}(t=0) & =k_{L} A
\end{aligned}
$$

where $\mathcal{H}_{\phi}$ and $\mathcal{L}_{\phi}$ denote the sensitivities to the parameter $\phi$ of the water levels in the reservoirs $\mathrm{H}$ and $\mathrm{L}$ respectively. 
Appendix A.2. Sensitivity equations for the Vensim model

Consider a perturbation in the parameter $\phi=H_{0}$. Then the perturbation approach leads to the following set of sensitivity equations

$$
\begin{array}{rlrl}
\frac{\mathrm{d} \mathcal{H}_{H_{0}}}{d t} & =0 & \text { for } H_{\min }<H<0 \\
\mathcal{H}_{H_{0}} & =0 & \text { for } H=H_{\min } \text { or } H=0 \\
\frac{\mathrm{d} \mathcal{S}_{H_{0}}}{d t} & =\frac{\partial X}{\partial S} \mathcal{S}_{H_{0}} Q_{\mathrm{H}}+X \frac{\partial Q_{\mathrm{H}}}{\partial H_{0}}-k_{\mathrm{S}} \mathcal{S}_{H_{0}} \\
\frac{\mathrm{d} \mathcal{R}_{H_{0}}}{d t} & =-\frac{\partial X}{\partial S} \mathcal{S}_{H_{0}} Q_{\mathrm{H}}+(1-X) \frac{\partial Q_{\mathrm{H}}}{\partial H_{0}}-k_{\mathrm{R}} \mathcal{R}_{H_{0}} \\
\mathcal{Q}_{H_{0}} & =A\left(k_{\mathrm{R}} \mathcal{R}_{H_{0}}+k_{\mathrm{S}} \mathcal{S}_{H_{0}}\right) \\
\mathcal{H}_{H_{0}}(t=0) & =1 \\
\mathcal{S}_{H_{0}}(t=0) & =0 \\
\mathcal{R}_{H_{0}}(t=0) & =0 \\
\mathcal{Q}_{H_{0}}(t=0) & =0
\end{array}
$$

Note that the term $\partial X / \partial S$ is equivalent to a dirac impulse which is turned on whenever $S=S_{\text {sill }}$ (see demonstration in Appendix B). Also note that the de-activation of the threshold means that the inflow rate $X Q_{\mathrm{H}}$ into the reservoir $\mathrm{S}$ is lower than the outflow rate $k_{\mathrm{S}} S$ from the reservoir $\mathrm{S}$ towards the spring. Since the specific discharge coefficient of the inflow is much greater than that of the outflow, the de-activation of $S_{\text {sill }}$ requires that the outflow from the reservoir $\mathrm{H}$ be zero $\left(\varepsilon_{\mathrm{H}}=0\right.$ and therefore $\left.Q_{\mathrm{H}}=0\right)$.

Similarly, for a perturbation in $\phi=S_{0}$

$$
\begin{aligned}
\frac{\mathrm{d} \mathcal{H}_{S_{0}}}{d t} & =0 \\
\frac{\mathrm{d} \mathcal{S}_{S_{0}}}{d t} & =\frac{\partial X}{\partial S} \mathcal{S}_{S_{0}} Q_{\mathrm{H}}-k_{\mathrm{S}} \mathcal{S}_{S_{0}} \\
\frac{\mathrm{d} \mathcal{R}_{S_{0}}}{d t} & =-\frac{\partial X}{\partial S} \mathcal{S}_{S_{0}} Q_{\mathrm{H}}-k_{\mathrm{R}} \mathcal{R}_{S_{0}} \\
\mathcal{Q}_{S_{0}} & =A\left(k_{\mathrm{R}} \mathcal{R}_{S_{0}}+k_{\mathrm{S}} \mathcal{S}_{S_{0}}\right) \\
\mathcal{H}_{S_{0}}(t=0) & =0 \\
\mathcal{S}_{S_{0}}(t=0) & =1 \\
\mathcal{R}_{S_{0}}(t=0) & =0 \\
\mathcal{Q}_{S_{0}}(t=0) & =k_{\mathrm{S}} A
\end{aligned}
$$

Lastly, a perturbation in $\phi=R_{0}$ yields

$$
\begin{aligned}
\frac{\mathrm{d} \mathcal{H}_{R_{0}}}{d t} & =0 \\
\frac{\mathrm{d} \mathcal{S}_{R_{0}}}{d t} & =0 \\
\frac{\mathrm{d} \mathcal{R}_{R_{0}}}{d t} & =-k_{\mathrm{R}} \mathcal{R}_{R_{0}} \\
\mathcal{Q}_{R_{0}} & =A\left(k_{\mathrm{R}} \mathcal{R}_{R_{0}}+k_{\mathrm{S}} \mathcal{S}_{R_{0}}\right) \\
\mathcal{H}_{R_{0}}(t=0) & =0 \\
\mathcal{S}_{R_{0}}(t=0) & =0 \\
\mathcal{R}_{R_{0}}(t=0) & =1 \\
\mathcal{Q}_{R_{0}}(t=0) & =k_{\mathrm{R}} A
\end{aligned}
$$




\section{Appendix B. Sensitivity source term $\partial Q_{\mathrm{H}} / \partial H_{0}$ (Vensim model)}

This Appendix details the calculation of the term $\partial Q_{\mathrm{H}} / \partial H_{0}$ that appear in equations (A.3c) and (A.3d). Denote by $t_{H}$ the time of the first overflow of the reservoir $\mathrm{H}$. The overflow discharge is a discontinuous function of time:

$$
\begin{array}{ll}
Q_{\mathrm{H}}=0 & \text { for } t<t_{H} \\
Q_{\mathrm{H}}=P-\mathrm{ET} & \text { for } t \geq t_{H}
\end{array}
$$

Assume that $H_{0}$ is perturbed by an amount $\delta H_{0}>0$. Due to the perturbation in $H_{0}$, the time of the overflow $t_{H}$ is advanced by a time $\delta t$ (see Figure B.12). The difference in the outflow between $t_{H}-\delta t$ and $t_{H}$ that results from the perturbation $\delta H_{0}$ is

$$
\int_{t_{H}-\delta t}^{t_{H}} \delta Q_{\mathrm{H}} d t=\int_{t_{H}-\delta t}^{t_{H}}(P-\mathrm{ET}) d t
$$

As $\delta H_{0}$ tends to zero, equation (B.2) can be approximated as

$$
\delta Q_{\mathrm{H}} \delta t=(P-\mathrm{ET}) \delta t
$$

Similarly, the difference in the filling of the reservoir $\mathrm{H}$ that results from the perturbation $\delta H_{0}$ can be expressed as

$$
\delta H_{0}=-(P-\mathrm{ET}) \delta t
$$

Combining equations (B.3) and (B.4) leads to

$$
\frac{\delta Q_{\mathrm{H}}}{\delta H_{0}} \delta t=1
$$

The sensitivity of the overflow discharge to the perturbation in $H_{0}$ is defined as

$$
\frac{\partial Q_{\mathrm{H}}}{\partial H_{0}}=\lim _{\delta H_{0} \rightarrow 0} \frac{\delta Q_{\mathrm{H}}}{\delta H_{0}}
$$

and verifies

$$
\begin{gathered}
\left(\frac{\partial Q_{\mathrm{H}}}{\partial H_{0}}\right)_{t \rightarrow t_{H}}+\infty \\
\int_{t_{H}^{-}}^{t_{H}^{+}} \frac{\partial Q_{\mathrm{H}}}{\partial H_{0}}=1 \\
\left(\frac{\partial Q_{\mathrm{H}}}{\partial H_{0}}\right)_{t<t_{H}}=0 \\
\left(\frac{\partial Q_{\mathrm{H}}}{\partial H_{0}}\right)_{t>t_{H}}=0
\end{gathered}
$$

The function $\partial Q_{\mathrm{H}} / \partial H_{0}$ is thus a Dirac function of magnitude $1 \mathrm{~s}^{-1}$.

\section{Appendix C. Validity of local uncertainty estimates}

The aim of this Appendix is to check the validity of the local sensitivity and uncertainty estimates by comparison against empirical estimates. 


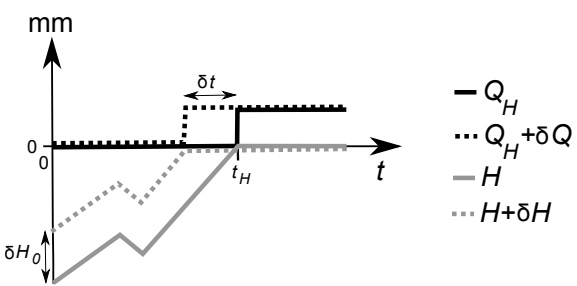

Figure B.12: Vensim model. Calculation of the term $\partial Q_{\mathrm{H}} / \partial H_{0}$. Influence of a perturbation in the inital water level $H_{0}$ on the water level $H$ and on the overflow discharge $Q_{\mathrm{H}}$.

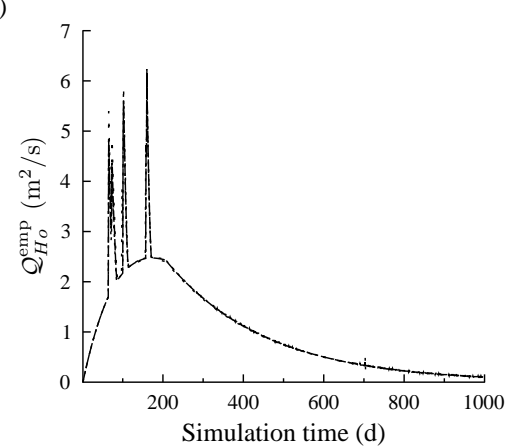

b)

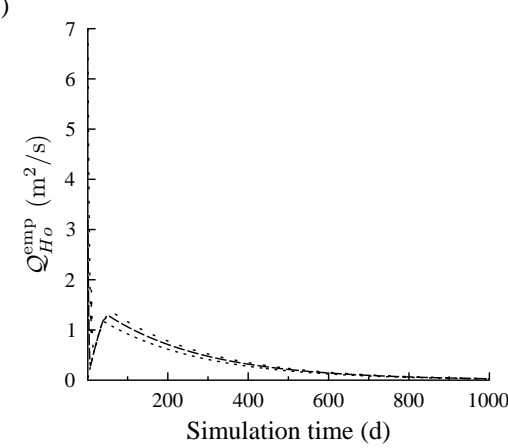

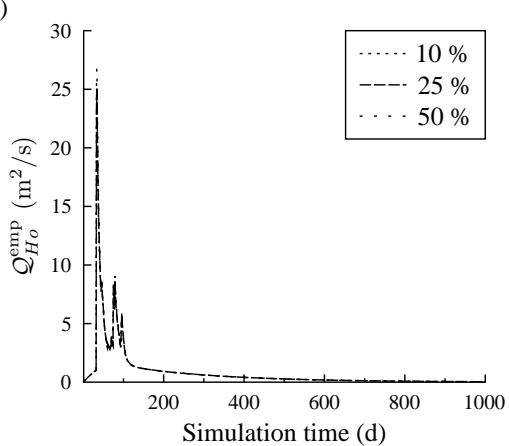

Figure C.13: Hysteresis-based model. Discharge sensitivity estimates for a perturbation in the initial water level $H_{0}$. Empirical estimates for: a) the computational example 1, b) the computational example 2, c) the computational example 3 . The simulation parameters are specified in Table 2.

\section{Appendix C.1. Case of the hysteresis-based model}

Since the hysteresis-based model is linear with respect to a perturbation in the parameter $L_{0}$, the validity of the local sensitivity and uncertainty analyses for a perturbation in $L_{0}$ need not to be checked.

The validity of the linear approximation for perturbations in $H_{0}$ is first checked by a graphic comparison between the local and empirical discharge sensitivities estimates. Figure C.13 shows the empirical discharge sensitivity $\mathcal{Q}_{H_{0}}^{\mathrm{emp}}$ computed based on perturbations $\Delta H_{0}$ ranging from 10 to $50 \%$ of the nominal value of $H_{0}$. The visual comparison of the empirical (Figure C.13) and local (Figures 7.a2, 8.a2 and 9.a2 sensitivity estimates shows a good agreement between the empirical and local approaches. The corresponding empirical and local uncertainties on the Nash criterion are given in Table C.7. The relative error on the Nash uncertainty estimate is at maximum $7 \%$ for a $50 \%$ perturbation in $H_{0}$, which confirms the suitability of the local approach.

\section{Appendix C.2. Vensim model}

Since the Vensim model is linear with respect to a perturbation in the parameter $R_{0}$, the validity of the local sensitivity and uncertainty analyses with respect to a perturbation in $R_{0}$ need not to be checked.

The validity of the linear approximation with respect to a perturbation in $S_{0}$ or $H_{0}$ is first checked by a graphic comparison between the local and empirical discharge sensitivity estimates. Experimental sensitivities are computed based on the results of two simulations. In the second simulation, the investigated parameter $\phi_{0}$ is modified by an amount $\Delta \phi_{0}$ as compared to the first simulation value. The empirical sensitivity $\mathcal{Q}_{\phi_{0}}^{\text {emp }}$ of the spring discharge to the parameter $\phi_{0}$ is approximated as the ratio of the difference between the results of the two simulations runs to the perturbation $\Delta \phi_{o}$

$$
\mathcal{Q}_{\phi_{0}(t)}^{\mathrm{emp}}=\frac{Q_{\left(\phi_{0}+\Delta \phi_{0}, t\right)}-Q_{\left(\phi_{0}, t\right)}}{\Delta \phi_{0}}
$$

Figure C.14a shows the empirical discharge sensitivity estimates $\mathcal{Q}_{S_{0}}^{\mathrm{emp}}$ for $\Delta S_{0}$ ranging from 10 to $50 \%$ of the nominal value of $S_{0}$. The empirical estimates must be compared to the local estimates which are plotted 


\begin{tabular}{cccc}
\hline Example $^{\circ}$ & $\Delta H_{0}(\%)$ & $\Delta \mathcal{N}_{\phi}^{\text {emp }}(\%)$ & $\Delta \mathcal{N}_{\phi}^{\text {loc }}(\%)$ \\
\hline \hline \multirow{2}{*}{1} & 10 & $1.9 \times 10^{-2}$ & $1.9 \times 10^{-2}$ \\
& 25 & $5.0 \times 10^{-2}$ & $4.8 \times 10^{-2}$ \\
& 50 & $1.0 \times 10^{-1}$ & $9.6 \times 10^{-2}$ \\
\hline \multirow{2}{*}{2} & 10 & $2.4 \times 10^{-3}$ & $2.4 \times 10^{-3}$ \\
& 25 & $6.3 \times 10^{-3}$ & $6.0 \times 10^{-3}$ \\
& 50 & $1.1 \times 10^{-2}$ & $1.2 \times 10^{-2}$ \\
\hline \multirow{3}{*}{3} & 10 & $7.5 \times 10^{-3}$ & $7.6 \times 10^{-3}$ \\
& 25 & $1.8 \times 10^{-2}$ & $1.9 \times 10^{-2}$ \\
& 50 & $3.6 \times 10^{-2}$ & $3.8 \times 10^{-2}$ \\
\hline
\end{tabular}

Table C.7: Hysteresis-based model. Empirical $\left(\Delta \mathcal{N}_{\phi}^{\text {emp }}\right)$ vs local $\left(\Delta \mathcal{N}_{\phi}^{\text {loc }}\right)$ uncertainty estimates of the Nash criterion over the calibration period (days 366 to 731 ).

in Figures 7.b2, 8.b2 and 9.b2. The visual comparison of the local and empirical sensitivities shows a strong difference between both, even for a $10 \%$ perturbation. The empirical sensitivities do show peaks by the date the threshold $S_{\text {sill }}$ is activated. However, empirical sensitivities also exhibit a number of supplementary peaks. Figure C.14b shows the empirical estimates $\mathcal{Q}_{H_{0}}^{\mathrm{emp}}$ of the discharge sensitivity computed based on perturbations $\Delta H_{0}$ ranging from 10 to $50 \%$ of the nominal value of $H_{0}$. The empirical estimates must be compared to the local sensitivities which are plotted in Figures 7.c2, 8.c2 and 9.c2. A visual comparison of the local and empirical sensitivities shows a strong difference between both. However, the situation is the reverse of that of a perturbation in $S_{0}$ as the empirical sensitivities lack a number of additional peaks compared to the local sensitivities.

The comparison of the empirical and local estimates of the uncertainty on the Nash criterion (see values in Table C.8) confirms the failure of the local approach for the uncertainty estimation.

The poor performance of the local uncertainty analysis may be associated to two factors: (i) the time discretization adopted for the solution of the model equations and (ii) the dynamics of the reservoir. Indeed, the reservoir $\mathrm{S}$ is characterized by a high storage and a slow drainage. As a consequence, the perturbation $\Delta S_{0}$ considered is important as compared to the daily changes in the water level. A perturbation in $S_{0}$ is likely to strongly modify the number of activations of the switch in the distribution coefficient and therefore the number of peaks in the sensitivity to $S_{0}$. On the other hand, the daily changes in the water level in the reservoir $\mathrm{H}$ are large compared to the perturbations $\Delta H_{0}$ considered. At a daily time step, the result is that the perturbation in $S_{0}$ is not likely to trigger a switch in the distribution coefficient. The case of the simulation 2 is somewhat different. The perturbation $\Delta H_{0}<0$ results in a complete emptying of the reservoir H. Since the emptying occurs before the first overflow, the propagation of the sensitivity to $H_{0}$ is completely stopped, as explained in Section 3.3.3.

\section{References}

[1] T. Wagener, H. S. Wheater, H. V. Gupta, Rainfall-runoff modelling in gauged and ungauged catchments, Imperial College Press, London, 2004. URL http: //www. icpress.co.uk/environsci/p335.html

[2] J. C. Refsgaard, Validation and intercomparison of different updating procedures for real-time forecasting, Nordic Hydrology 28 (2) (1997) 65-84. doi:10.2166/nh.1997.005.

[3] A. H. Weerts, G. Y. H. El Serafy, Particle filtering and ensemble Kalman filtering for state updating with hydrological conceptual rainfall-runoff models, Water Resources Research 42 (9) (2006) W09403-. doi:10.1029/2005WR004093.

[4] G. van Delft, G. Y. El Serafy, A. W. Heemink, The ensemble particle filter (EnPF) in rainfall-runoff models, Stochastic Environmental Research and Risk Assessment 23 (8) (2009) 1203-1211. doi:10.1007/s00477-008-0301-z.

[5] D.-J. Seo, L. Cajina, R. Corby, T. Howieson, Automatic state updating for operational streamflow forecasting via variational data assimilation, Journal of Hydrology 367 (3-4) (2009) 255-275. doi:10.1016/j.jhydrol.2009.01.019.

[6] C. Perrin, C. Michel, V. Andreassian, Does a large number of parameters enhance model performance? Comparative assessment of common catchment model structures on 429 catchments, Journal of Hydrology 242 (3-4) (2001) $275-301$. doi:10.1016/S0022-1694(00)00393-0. 

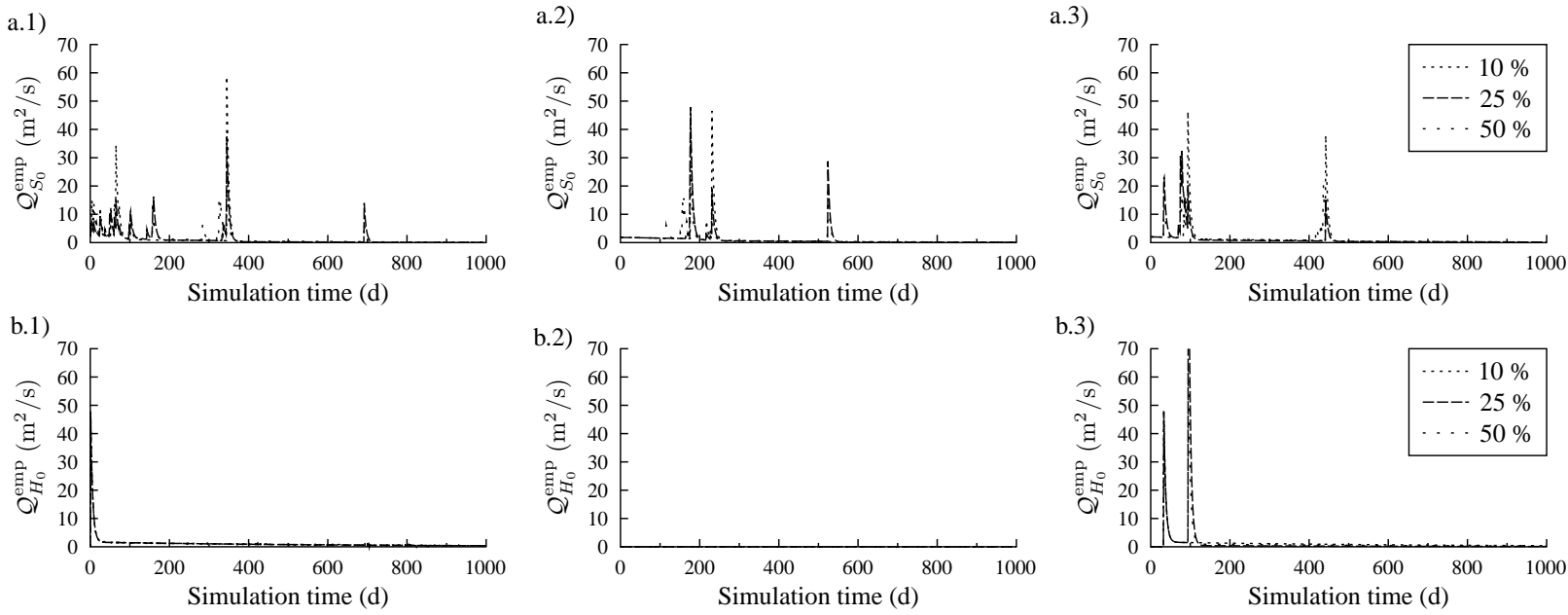

Figure C.14: Empirical discharge sensitivity estimates for a perturbation in: a) the initial water level in the reservoir S, b) the initial water level in the reservoir $\mathrm{H}$ for 1) the computational example 1,2 ) the computational example 2,3 ) the computational example 3. The simulation parameters are given in Table 4.

\begin{tabular}{|c|c|c|c|c|}
\hline & Example $n^{\circ}$ & $\Delta \phi_{o}(\%)$ & $\Delta \mathcal{N}_{\phi}^{\text {emp }}(\%)$ & $\Delta \mathcal{N}_{\phi}^{\text {loc }}(\%)$ \\
\hline \multirow{9}{*}{$\begin{array}{l}0 \\
\| \\
\theta \\
\theta\end{array}$} & \multirow{3}{*}{1} & 10 & $1.9 \times 10^{-2}$ & $1.7 \times 10^{-2}$ \\
\hline & & 25 & $5.1 \times 10^{-2}$ & $4.3 \times 10^{-2}$ \\
\hline & & 50 & $1.3 \times 10^{-2}$ & $8.7 \times 10^{-2}$ \\
\hline & \multirow{3}{*}{2} & 10 & 0 & $9.2 \times 10^{-3}$ \\
\hline & & 25 & 0 & $4.2 \times 10^{-2}$ \\
\hline & & 50 & 0 & $1.2 \times 10^{-2}$ \\
\hline & \multirow{3}{*}{3} & 10 & $1.8 \times 10^{-1}$ & $3.4 \times 10^{-1}$ \\
\hline & & 25 & $1.3 \times 10^{-1}$ & $7.8 \times 10^{-1}$ \\
\hline & & 50 & $5.7 \times 10^{-1}$ & 1.6 \\
\hline \multirow{9}{*}{$\begin{array}{l}0 \\
\| \\
\theta\end{array}$} & \multirow{3}{*}{1} & 10 & $2.9 \times 10^{-1}$ & 2.4 \\
\hline & & 25 & 4.6 & 5.9 \\
\hline & & 50 & 6.3 & 12 \\
\hline & \multirow{3}{*}{2} & 10 & $3.2 \times 10^{-1}$ & $1.4 \times 10^{-1}$ \\
\hline & & 25 & 2.8 & $3.4 \times 10^{-1}$ \\
\hline & & 50 & 7.2 & $6.8 \times 10^{-1}$ \\
\hline & \multirow{3}{*}{3} & 10 & 3.5 & 1.8 \\
\hline & & 25 & 4.3 & 4.6 \\
\hline & & 50 & 27 & 9.2 \\
\hline
\end{tabular}

Table C.8: Vensim model. Empirical $\left(\Delta \mathcal{N}_{\phi}^{\text {emp }}\right)$ vs local $\left(\Delta \mathcal{N}_{\phi}^{\text {loc }}\right)$ uncertainty estimates for the Nash criterion over the calibration period (days 366 to 731 ). 
[7] S. Tritz, V. Guinot, H. Jourde, Modelling the behaviour of a karst system catchment using non linear hysteretic conceptual model, Journal of Hydrology 397 (3-4) (2011) 250-262. doi:10.1016/j.jhydrol.2010.12.001.

[8] S. Mouelhi, Vers une chaîne cohérente de modèles pluie-débit conceptuels globaux aux pas de temps pluriannuel, annuel, mensuel et journalier, Ph.D. thesis, Cemagref d'Antony, ENGREF (2003).

URL http://tel.archives-ouvertes.fr/tel-00005696/fr/

[9] N. Le Moine, Le bassin versant de surface vu par le souterrain : Une voie d'amélioration des performances et du réalisme des modèles pluie-débit ?, Ph.D. thesis, Université Pierre et Marie Curie (2010). URL http://hydrologie.org/THE/LE_MOINE.pdf

[10] P. Fleury, Sources sous-marines et aquifères karstiques côtiers méditerranéens. Fonctionnement et caractérisation, Ph.D. thesis, Université Paris VI - Pierre et Marie Curie (2005). URL http: //hydrologie.org/THE/FLEURY.pdf

[11] L. Bruxelles, Dépots et altérites des plateaux du Larzac central: Causses de l'Hospitalet et de Campestre (Aveyron, Gard, Hérault). Évolution morphogénique, consequences géologiques et implications pour l'amenagement, Ph.D. thesis, Université de Provence (2001).

[12] J. Ricard, M. Bakalowicz, Connaissance, aménagement et protection des ressources en eau du Larzac septentrional, Aveyron (France), Tech. Rep. R38953, BRGM (1996). URL http: //www. brgm.fr/Rapport?code=RR-38953-FR

[13] C. Thornthwaite, An approach toward a rational classification of climate, Geographical Review 38 (1) (1948) 55-94. URL http: //www.jstor.org/stable/210739

[14] T. Jacob, R. Bayer, J. Chery, H. Jourde, N. Le Moigne, J.-P. Boy, J. Hinderer, B. Luck, P. Brunet, Absolute gravity monitoring of water storage variation in a karst aquifer on the Larzac plateau (Southern France), Journal of Hydrology 359 (2008) 105-117. doi:10.1016/j.jhydrol.2008.06.020.

[15] C. Bézès, Contribution à la modélisation des systèmes aquifères karstiques; établissement du modèle BEMER; son application à quatre systèmes karstiques du midi de la France, Ph.D. thesis, Université Montpellier II (1976).

[16] A. Hreiche, Modélisation conceptuelle de la transformation pluie-débit dans le contexte méditerranéen, Ph.D. thesis, Université Montpellier II (2003).

URL http://tel.archives-ouvertes.fr/tel-00004188/fr/

[17] B. Blavoux, J. Mudry, J.-M. Puig, The karst system of the Fontaine de Vaucluse (South-eastern France), Environmental Geology 19 (3) (1992) 215-225. doi:10.1007/BF01704088.

[18] A. Pulido-Bosch, A. Padilla-Benitez, D. Dimitov, , M. Machkova, The discharge variability of some karst springs in Bulgaria studied by time series analysis., Hydrological Sciences Journal 40 (4) (1995) 517. doi:10.1080/02626669509491436.

[19] O. Bonacci, Analysis of long-term (1878-2004) mean annual discharges of the karst spring Fontaine de Vaucluse (France), Acta Carsologica 36 (1) (2007) 151-156.

[20] D. Cacuci, Sensitivity and Uncertainty Analysis: Theory, Sensitivity and Uncertainty Analysis, CRC Press, 2003.

[21] A. Murphy, Skill scores based on the mean square error and their relationships to the correlation coefficient, Monthly Weather Review 116 (12) (1988) 2417-2424. doi:10.1175/1520-0493(1988)116<2417:SSBOTM>2.0.CO;2.

[22] S. Weglarczyk, The interdependence and applicability of some statistical quality measures for hydrological models, Journal of Hydrology 206 (1-2) (1998) 98-103. doi:10.1016/S0022-1694(98)00094-8.

[23] H. V. Gupta, H. Kling, K. K. Yilmaz, G. F. Martinez, Decomposition of the mean squared error and NSE performance criteria: Implications for improving hydrological modelling, Journal of Hydrology 377 (1-2) (2009) 80-91. doi:10.1016/j.jhydrol.2009.08.003.

[24] R. Moussa, N. Chahinian, C. Bocquillon, Distributed hydrological modelling of a Mediterranean mountainous catchment - Model construction and multi-site validation, Journal of Hydrology 337 (2007) 35-51. doi:10.1016/j.jhydrol.2007.01.028.

[25] P. O. Yapo, H. V. Gupta, S. Sorooshian, Multi-objective global optimization for hydrologic models, Journal of Hydrology 204 (1-4) (1998) 83-97. doi:10.1016/S0022-1694(97)00107-8.

[26] H. Madsen, Automatic calibration of a conceptual rainfall-runoff model using multiple objectives, Journal of Hydrology 235 (3-4) (2000) 276-288. doi:10.1016/S0022-1694(00)00279-1.

[27] M. R. Jazayeri Noushabadi, Characterisation of relationships between fracture network and flow-path network in fractured and karstic reservoirs numerical modelling and field investigation (Lez aquifer, Southern France), Ph.D. thesis, Université Montpellier II (2009).

URL http: //www.hydrosciences.org/IMG/pdf/PHD_2009_M_Reza_Jazayeri.pdf 